\title{
Deletion or inhibition of soluble epoxide hydrolase protects against brain damage and reduces microglia-mediated neuroinflammation in traumatic brain injury
}

\author{
Tai-Ho Hung ${ }^{1}$, Song-Kun Shyue ${ }^{2}$, Chun-Hu Wu ${ }^{3}$, Chien-Cheng Chen ${ }^{4}$, Chao-Chang \\ Lin ${ }^{4}$, Che-Feng Chang ${ }^{5}$ and Szu-Fu Chen ${ }^{4,6}$ \\ ${ }^{1}$ Department of Obstetrics and Gynecology, Chang Gung Memorial Hospital at Taipei and College of Medicine, Chang Gung \\ University, Taoyuan, Taiwan, Republic of China \\ ${ }^{2}$ Institute of Biomedical Sciences, Academia Sinica, Taipei, Taiwan, Republic of China \\ ${ }^{3}$ Graduate Institute of Life Sciences, National Defense Medical Center, Taipei, Taiwan, Republic of China \\ ${ }^{4}$ Department of Physical Medicine and Rehabilitation, Cheng Hsin General Hospital, Taipei, Taiwan, Republic of China \\ ${ }^{5}$ Department of Neurology, Yale University School of Medicine, New Haven, Connecticut, USA \\ ${ }^{6}$ Departments of Physiology and Biophysics, National Defense Medical Center, Taipei, Taiwan, Republic of China \\ Correspondence to: Szu-Fu Chen, email: szufuchen@yahoo.com.tw \\ Keywords: soluble epoxide hydrolase, traumatic brain injury, microglia, inflammation, AUDA \\ Received: February 15, $2017 \quad$ Accepted: August 17, $2017 \quad$ Published: September 21, 2017 \\ Copyright: Hung et al. This is an open-access article distributed under the terms of the Creative Commons Attribution License 3.0 \\ (CC BY 3.0), which permits unrestricted use, distribution, and reproduction in any medium, provided the original author and source \\ are credited.
}

\section{ABSTRACT}

Traumatic brain injury (TBI) induces a series of inflammatory processes that contribute to neuronal damage. The present study investigated the involvement of soluble epoxide hydrolase ( $\mathrm{SEH}$ ) in neuroinflammation and brain damage in mouse TBI and in microglial cultures. The effects of genetic deletion of SEH and treatment with an SEH inhibitor, 12-(3-adamantan-1-yl-ureido)-dodecanoic acid (AUDA), on brain damage and inflammatory responses were evaluated in mice subjected to controlled cortical impact. The anti-inflammatory mechanism of SEH inhibition/deletion was investigated in vitro. TBI-induced an increase in SEH protein level in the injured cortex from $1 \mathrm{~h}$ to 4 days and SEH was expressed in microglia. Genetic deletion of sEH significantly attenuated functional deficits and brain damage up to 28 days postTBI. Deletion of SEH also reduced neuronal death, apoptosis, brain edema, and BBB permeability at 1 and 4 day(s). These changes were associated with markedly reduced microglial/macrophage activation, neutrophil infiltration, matrix metalloproteinase-9 activity, inflammatory mediator expression at 1 and 4 day(s), and epoxyeicosatrienoic acid (EET) degradation at 1 and 4 day(s). Administration of AUDA attenuated brain edema, apoptosis, inflammatory mediator upregulation and EET degradation at 4 days. In primary microglial cultures, AUDA attenuated both LPS- or IFN- $y-s t i m u l a t e d$ nitric oxide (NO) production and reduced LPS- or IFN- $y$-induced p38 MAPK and NF-KB signaling. Deletion of sEH also reduced IFN-y-induced NO production. Moreover, AUDA attenuated N2A neuronal death induced by BV2 microglial-conditioned media. Our results suggest that inhibition of SEH may be a potential therapy for TBI by modulating the cytotoxic functions of microglia. 


\section{INTRODUCTION}

Traumatic brain injury (TBI) is the leading cause of mortality and long-term disability among young adults worldwide [1]. TBI induces brain damage due to initial physical disruption of tissue (primary injury) and subsequent development of excitotoxicity, oxidative damage, and inflammation (secondary injury) [2]. Of these, cerebral inflammation is regarded as a key factor in the secondary injury cascade and contributes to neuronal death and neurological deterioration $[3,4]$. Post-traumatic inflammatory responses are mediated by activation of microglia and recruitment of peripheral leukocytes to the cerebral parenchyma [4]. Activated microglia produce multiple proinflammatory mediators, including cytokines, chemokines, nitric oxide (NO) and other factors with cytotoxic effects. Overproduction of these mediators contributes to neuronal damage and blood-brain barrier (BBB) disruption, which is considered to be the major cause of vasogenic brain edema and subsequent brain injury [3-5]. Microglia can be further activated by various signals released from dying neurons or by direct contact with damaged neurons, thus further amplifying neuronal damage $[4,6]$. Activated microglia can induce mitochondria-dependent apoptosis via production of reactive oxygen and nitrogen species [6]. Additionally, proinflammatory cytokines derived from microglia can activate receptor-dependent apoptotic pathways via recruitment of adaptor molecules and caspase- 8 or -10 activation [7, 8]. Accordingly, inhibition of microglial activation and, therefore, production of inflammatory mediators has been suggested to be a potential therapeutic strategy for protecting the damaged brain in TBI $[9,10]$.

Epoxyeicosatrienoic acids (EETs), which are produced from arachidonic acid in a cytochrome P450catalyzed reaction, have potent anti-inflammatory actions [11]. Previous studies have shown that exogenous administration of 14,15- EET and increased expression of CYP epoxygenases in the brain are protective against experimental ischemic brain injury $[12,13]$. In vitro and in vivo studies have also shown that EETs possess potent anti-inflammatory effects [11, 12, 14, 15], suggesting that EETs signaling may suppress trauma-evoked neuroinflammation. EETs are broken down into less bioactive corresponding dihydroxyeicosatrienoic acids (DHETs) by soluble epoxide hydrolase enzyme (sEH), and inhibition of sEH increases EETs levels in tissues and plasma, thus enhancing the effects of EETs [11]. The significance of sEH in damaged brain is supported by evidence that the expression of this enzyme is significantly increased in rodent models of brain damage including cerebral ischemia [12], Parkinsonism [16], and seizures [17]. Clinically, patients with genetic polymorphisms that reduce sEH activity have improved outcomes after subarachnoid hemorrhage [18]. Genetic deletion or pharmacological inhibition of the epoxide hydrolase gene has also been shown to provide protection against experimental cerebral ischemia [19, 20], Parkinsonism [16] and seizure [17].

Although genetic deletion of sEH has been reported to improve functional outcomes after mouse TBI [21], little is known about the role of $\mathrm{sEH}$ in regulating microglia-induced neuroinflammation in brain damage. It is also unclear whether sEH can be activated by TBI or whether sEH inhibition has an impact on neuronal damage and brain edema. To address these issues, the present study aimed to examine the effects of pharmacological and genetic inhibition of sEH on long-term functional impairment, neuronal damage, and brain edema after experimental TBI in mice. We further aimed to investigate whether sEH inhibition attenuated TBI-induced microglial activation, thereby preventing neuronal damage in both cell and animal models.

\section{RESULTS}

\section{Increased SEH expression in mice after TBI}

We first verified the specificity of the sEH antibody by immunoblotting on the wild-type (WT) liver tissue (the positive control) and brain samples of sEH knockout (KO) mice (the negative control). Western blot analysis of liver and brain homogenates from WT mice revealed the presence of a dominant $\mathrm{SEH}$-immunoreactive band at $\sim 62 \mathrm{kDa}$, which was absent in the brain of sEH KO mice (Figure 1A), confirming the specificity of the antibody to sEH.

To investigate the possible participation of $\mathrm{SEH}$ in the pathogenesis of TBI, we first examined the expression and cellular localization of $\mathrm{SEH}$ in brains subjected to controlled cortical impact (CCI) injury. Compared with the sham control group, $\mathrm{CCI}$ induced an increase in $\mathrm{sEH}$ protein level in the injured cortex at $1 \mathrm{~h}, 3 \mathrm{~h}, 6 \mathrm{~h}, 12 \mathrm{~h}$, 1 day and 4 days (all $P<0.01$; Figure 1B). At 7 days after injury, the sEH protein level had decreased to the sham level. We also investigated the cellular localizations of sEH at 1 day post-injury or following sham surgery. Dual-label immunofluorescence demonstrated that sEH was expressed in microglia, neurons, astrocytes, and endothelial cells in the contusion margin of the injury core or sham-operated brains (Figure 1C). No immunoreactivity was observed in either hemisphere of sEH KO mice after CCI (Supplementary Figure 1).

\section{Deletion of SEH reduces long-term neurological deficits and brain tissue damage after TBI}

To assess whether sEH contributes to TBI, we first used a loss-of-function strategy to evaluate the effect of sEH deletion on behavioral recovery (Figures 2A-2E). The modified neurological severity score (mNSS) was used to measure global neurological deficits. At $3 \mathrm{~h}$ after injury, 


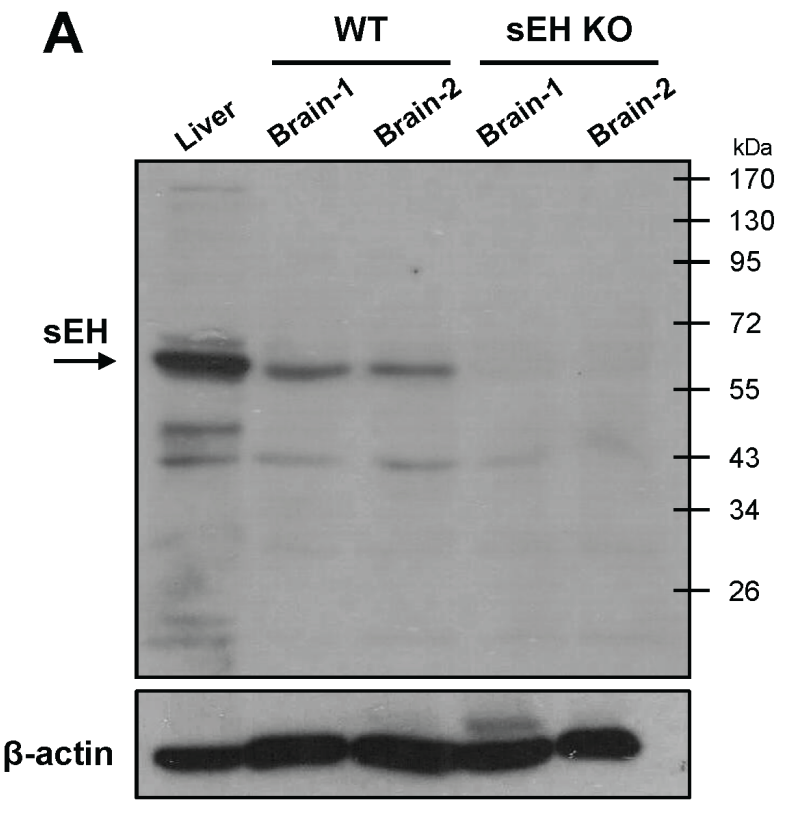

C

Sham

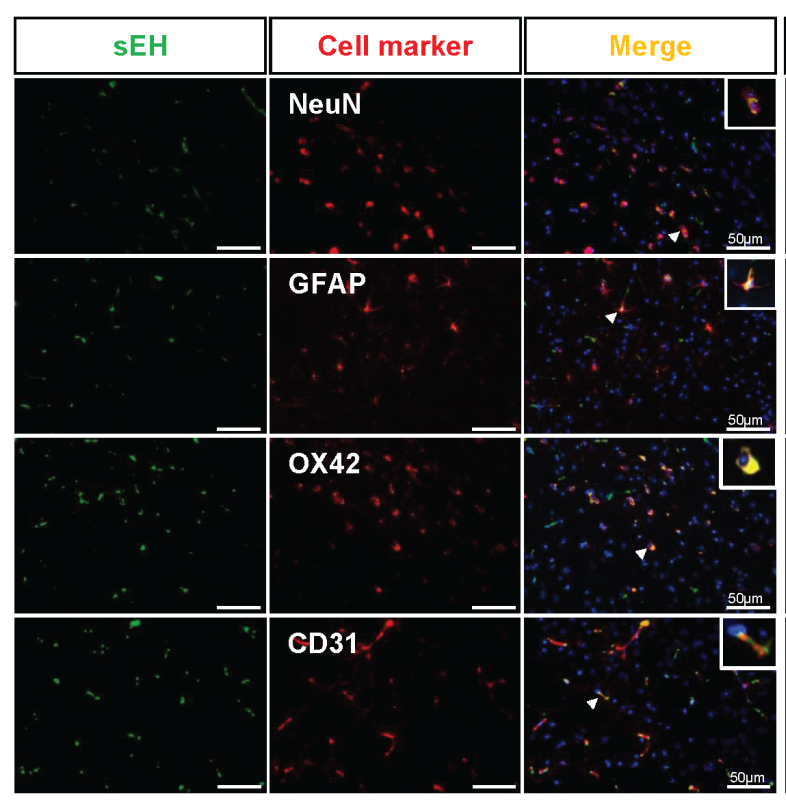

B

TBI

\section{Sham $1 \mathrm{~h} \quad 3 \mathrm{~h} \quad 6 \mathrm{~h} \quad 12 \mathrm{~h} \quad$ D1 $\quad$ D4 $\quad$ D7}

sEH
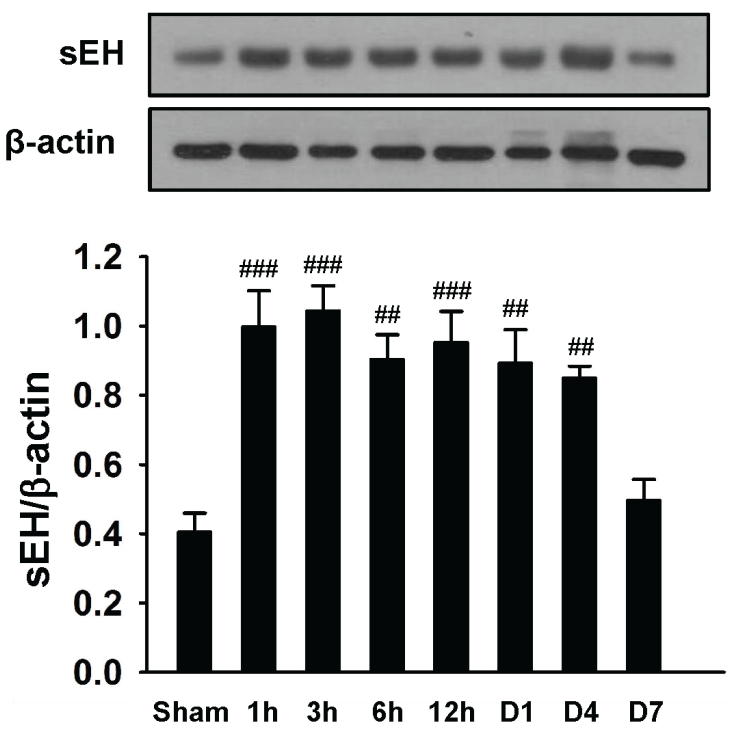

$\beta$-actin

Day 1 TBI

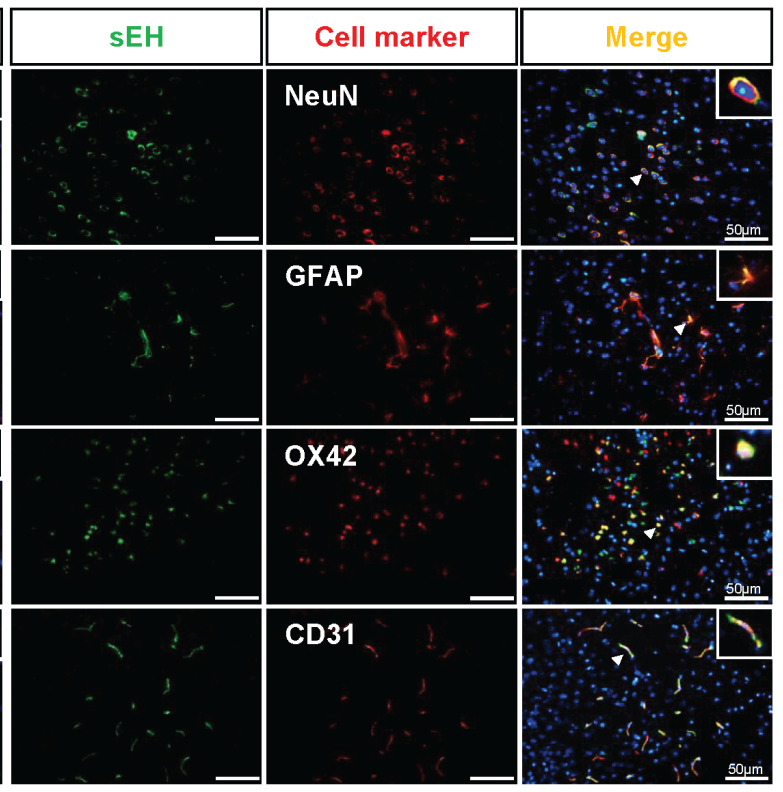

Figure 1: Upregulation of SEH protein expression in WT brains subjected to TBI. (A) Western blot analysis of mouse liver and brain tissues using anti-sEH antibody demonstrating a dominant band at $\sim 62 \mathrm{kDa}$ in the WT liver (lane 1) and WT brains (lanes 2 and 3), whereas no product was present in the sEH KO brains (lanes 4 and 5), confirming the specificity of the antibody. (B) Representative immunoblots of the sEH protein in the ipsilateral hemispheres of mice subjected to CCI injury or sham surgery. Bar graph of densitometric analysis of bands showing a significant increase in sEH protein level in the ipsilateral hemispheres of WT mice at $1 \mathrm{~h}, 3 \mathrm{~h}, 6 \mathrm{~h}, 12 \mathrm{~h}, 1 \mathrm{day}$ and 4 days post-TBI, compared with the sham-operated brains. At 7 days after injury, the sEH protein level had decreased to the sham level. (C) Identification of sEH -positive cells at 1 day post-TBI or sham surgery in the peri-contussional area by double immunofluorescence labeling. sEH immunoreactivity is shown in green, and immunolabeling of NeuN (neurons), GFAP (astrocytes), OX42 (microglia), or CD31 (endothelial cells) is shown in red. Co-localization is shown by yellow labeling. Arrowheads indicate the location of higher magnification images. sEH localized to neurons, astrocytes, microglia, and endothelial cells. Sections were stained with DAPI (blue) to show all nuclei. Values are mean \pm S.E.M; ${ }^{\#} P<0.01$, and ${ }^{\# \#} P<0.001$ vs. sham group $(\mathrm{n}=5-6$ mice / group, one-way ANOVA). The scale bar is $50 \mu \mathrm{m}$. 
there was no difference in mNSS between WT and sEH $\mathrm{KO}$ mice, indicating that injury severity was initially equal (Figure 2B). The mNSS scores were significantly lower for sEH KO mice than for WT mice at 1, 7, 14, 21, and 28 days (all $P<0.05$; Figure $2 \mathrm{~B}$ ). Rotarod and beam walking tests were employed to assess motor and coordination functions. Rotarod performance was significantly better in sEH KO mice compared with WT mice from 4 to 28 days (all $p<0.01$; Figure 2C). In the beam-walking test, sEH KO mice required significantly less time to cross the beam at 4, 7 and 21 days post-injury (all $P<0.05$; Figure 2D). The hindlimb scores were also significantly higher for sEH KO than for WT mice from 4 to 28 days (all $P$ $<0.05$; Figure 2E). However, there were no significant changes between the two groups in body weight (Figure $2 \mathrm{~F}$ ). Overall, these findings suggest that sEH deletion improves long-term neurobehavioral outcomes following CCI.

To test whether genetic deletion of $\mathrm{sEH}$ also has an impact on brain tissue damage, we next analyzed the contusion volume and the ipsilateral hemispheric enlargement, an indicator of brain swelling, at the acute phase of TBI. Deletion of the sEH gene significantly attenuated contusion volume to $83.9 \%$ of the WT level from $23.0 \pm 0.7 \mathrm{~mm}^{3}$ to $19.3 \pm 0.8 \mathrm{~mm}^{3}$ at day $1(P=$ 0.0051 ; Figure $2 \mathrm{H}$ ), and to $85.9 \%$ of the WT level from $20.5 \pm 0.7 \mathrm{~mm}^{3}$ to $17.6 \pm 0.6 \mathrm{~mm}^{3}$ at day $4(P=0.01$; Figure 2I). Similarly, sEH KO mice also displayed 26.4\% less ipsilateral hemispheric enlargement at day 1 (6.7 \pm $0.5 \%$ vs. $9.1 \pm 0.8 \%, P=0.0298$; Figure $2 \mathrm{H})$ and $53.2 \%$ less at day $4(3.7 \pm 0.8 \%$ vs. $7.9 \pm 0.8 \%, P=0.002$; Figure 2I). We next analyzed brain tissue damage and the remaining ipsilateral hemisphere volume during the chronic phase of TBI. Consistent with the results at 1 day and 4 days, CCI induced a pronounced tissue loss in the injured hemisphere at post-injury day 28 . The contusion volume in sEH KO mouse brains was only $72.8 \%$ of that in WT mouse brains $\left(9.9 \pm 0.8 \mathrm{~mm}^{3}\right.$ vs. $13.6 \pm 0.7 \mathrm{~mm}^{3}, P$ $=0.0046$; Figure $2 \mathrm{~J}$ ) at day 28. Likewise, there was greater preservation of brain tissue in $\mathrm{sEH} \mathrm{KO}$ mice $(78.9 \pm 1.3 \%$ of the contralateral hemisphere) compared with WT mice $(70.7 \pm 2.1 \%, P=0.006$; Figure $2 \mathrm{~J})$.

\section{Deletion of $\mathrm{SEH}$ reduces neuronal damage and apoptosis after TBI}

We further investigated whether deletion of $\mathrm{sEH}$ influenced neuronal damage and cell apoptosis at 1 day and 4 days post-injury. We chose these 2 time-points because previous studies have shown that Fluoro-Jade $\mathrm{B}$ and (FJB) and terminal deoxynucleotidyl transferasemediated dUTP-biotin nick end labeling (TUNEL) reactivity peak at 1 day after experimental TBI, last for over 3 days and are almost absent after 14 days [22, 23]. In line with the results of cresyl violet staining, the number of FJB-positive neurons in the contusion margin of the injury core was significantly reduced in $\mathrm{sEH} \mathrm{KO}$ mice compared with WT mice at both 1 day $(65.2 \pm 2.8$ vs. 77.8 \pm 1.5 cells/field, $P=0.002$; Figure $3 \mathrm{~A})$ and 4 days (53.2 \pm 2.5 vs. $65.3 \pm 3.3$ cells/field, $P=0.0117$; Figure $3 \mathrm{~A}$ ). Additionally, deletion of sEH significantly diminished the number of TUNEL-positive cells in the contusion margin at both 1 day $(55.9 \pm 2.2 \%$ vs. $65.7 \pm 2.3 \%, P=0.0105$; Figure $3 \mathrm{~B})$ and 4 days $(52.1 \pm 2.3 \%$ vs. $62.2 \pm 1.5 \%, P$ $=0.0034$; Figure 3B). The level of cleaved caspase-3, a final effector of apoptotic death, was significantly elevated at both tested time-points following CCI in both WT and sEH KO groups (all $P<0.001$; Figure 3D). The cleaved caspase-3 level in sEH KO mouse injured brains was significantly decreased to $65.9 \%(P<0.001)$ of the WT-level at 1 day and to $56.7 \%(P<0.001)$ of the WTlevel at 4 days (Figure 3D). Taken together, these results demonstrate that deletion of $\mathrm{sEH}$ provides neuroprotection following TBI.

\section{Deletion of sEH attenuates brain edema, BBB permeability, MMP-9 enzymatic activity and neutrophil infiltration after TBI}

To investigate the potential mechanism of $\mathrm{sEH}$ in regulating TBI-triggered inflammation, we first measured brain edema and BBB breakdown following CCI as both are a consequence of post-injury inflammation [24]. In both WT and sEH KO mice, brain water content in the ipsilateral hemisphere of the TBI groups was significantly higher than that in the sham groups at both 1 and 4 days (all $P<0.001$; Figure 4A). Compared with WT mice, sEH KO mice had significantly decreased brain water content in the ipsilateral hemisphere at both $1(83.7 \pm 0.6 \%$ vs. $86.5 \pm 0.3 \%, P=0.002$; Figure $4 \mathrm{~A})$ and 4 days $(81.0 \pm$ $0.4 \%$ vs. $82.7 \pm 0.6 \%, P=0.029$; Figure $4 \mathrm{~A})$. As BBB breakdown may result in the accumulation of circulating fluid and cause brain edema [25], we further evaluated whether deletion of $\mathrm{sEH}$ attenuated $\mathrm{BBB}$ breakdown, as determined by leakage of albumin-bound Evans blue into the brain. In both WT and sEH KO mice, there was a marked increase in Evans blue extravasation in the ipsilateral hemisphere of the TBI groups compared with the sham groups at both 1 and 4 days (all $p<0.001$; Figure 4B). The Evans blue content in the ipsilateral hemisphere of the WT groups was significantly attenuated by $\mathrm{sEH}$ deletion at both 1 day $(20.0 \pm 1.2 \mu \mathrm{g} / \mathrm{g}$ vs. $29.8 \pm 3.2 \mu \mathrm{g} / \mathrm{g}$; $P=0.002$; Figure 4B) and 4 days $(13.9 \pm 1.3 \mu \mathrm{g} / \mathrm{g}$ vs. 19.4 $\pm 0.9 \mu \mathrm{g} / \mathrm{g} ; p<0.001$; Figure 4B) post-TBI.

We also examined the effects of $\mathrm{sEH}$ deletion on two major proteins involved in the tight junctions of the $\mathrm{BBB}$, zonula occludens (ZO)-1 and claudin-5. In both WT and $\mathrm{sEH} \mathrm{KO}$ mice, TBI resulted in a significant decrease in both ZO- 1 and caludin-5 protein expression at 1 and 4 days after injury (all $p<0.01$; Figure 4C). However, there was no significant difference in ZO-1 nor claudin-5 expression between the two groups at either tested time- 
A
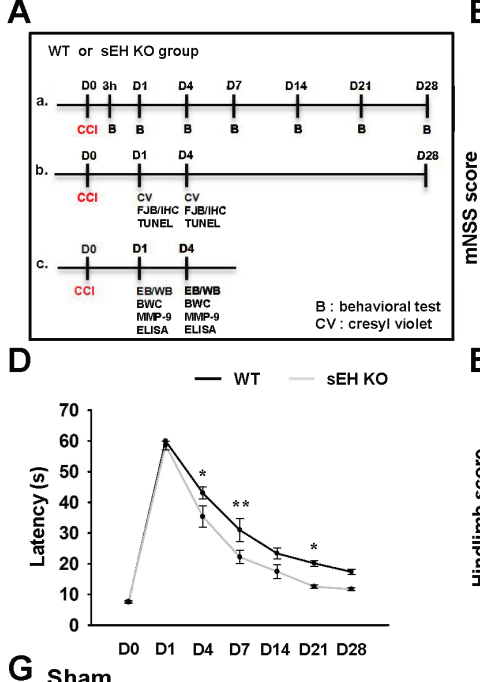

B

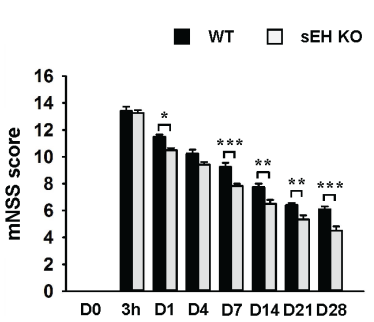

E

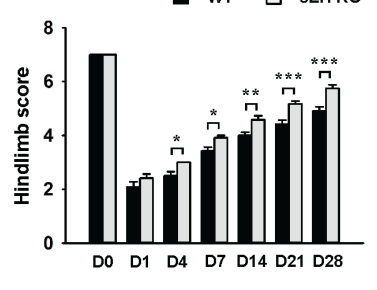

C
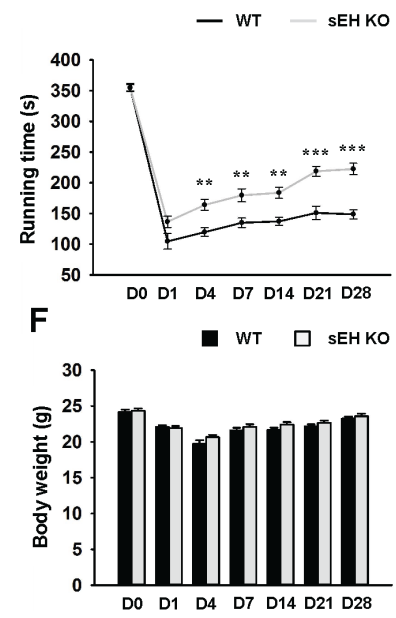
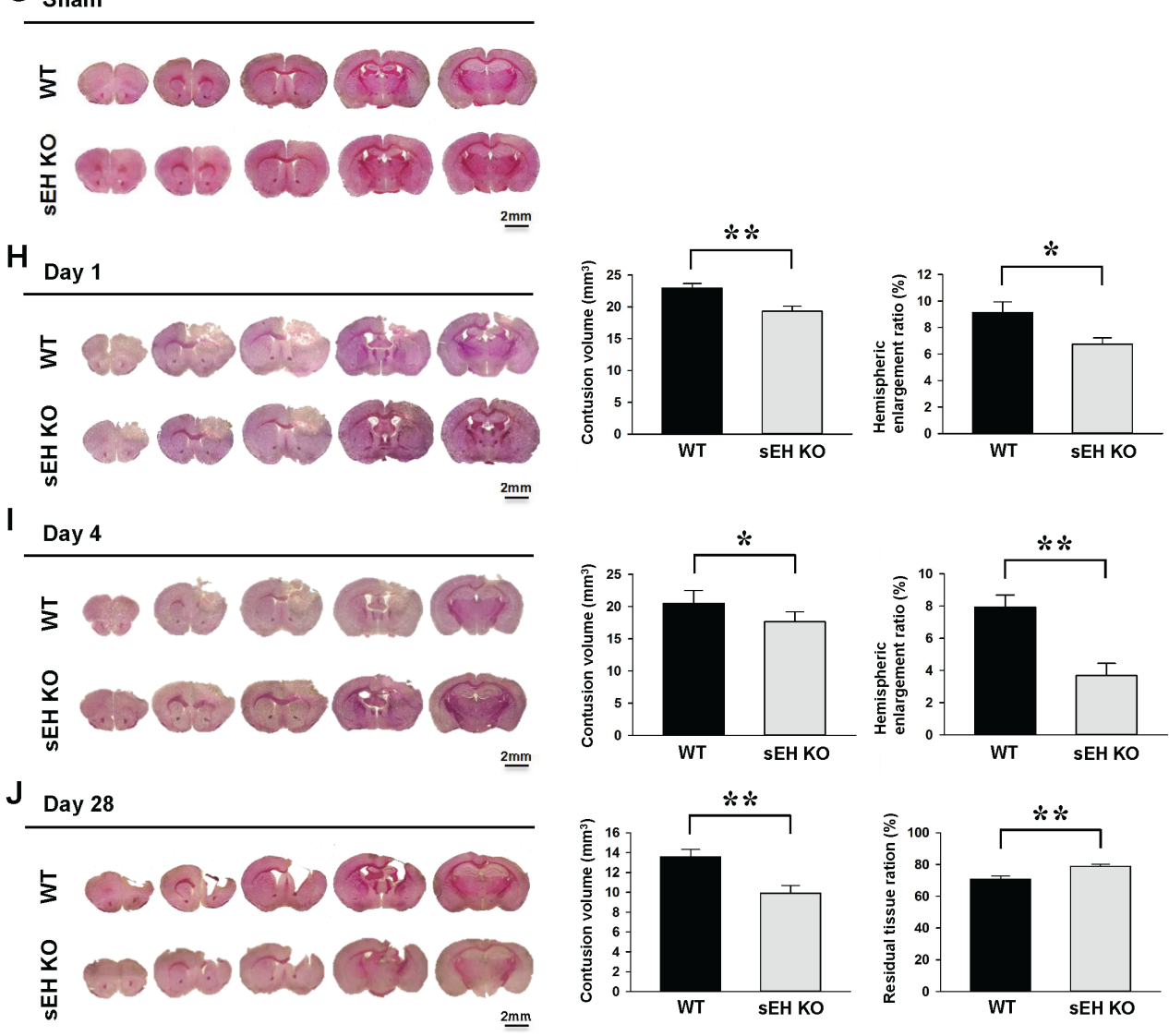

Figure 2: Deletion of SEH improved long-term neurobehavioral functions and reduced brain tissue damage after TBI. (A) Experimental design and animal groups classification. TBI: traumatic brain injury; B: behavioral test; CV: cresyl violet; IF: immunofluorescence staining; FJB: fluoro-jade Bs staining; IHC: immunohistochemical staining; TUNEL: terminal deoxynucleotidyl transferase-mediated dUTP-nick end labeling; EB: Evans Blue; WB: Western blots; BWC: brain water content; MMP-9: matrix metalloproteinase-9; ELISA: enzyme-linked immunosorbent assay. Deletion of sEH (compared with WT control) significantly (B) reduced the modified neurological severity score (mNSS) at 1, 7, 14, 21 and 28 days post-injury, (C) improved the rotarod performance from 4 to 28 days post-injury, (D) reduced the beam walk traversing time at 4, 7 and 21 days, and (E) improved hindlimb function from 4 to 28 days. (F) There were no significant differences in body weight change between sEH KO and WT mice during the 28-day observation period post-TBI. Representative cresyl violet-stained brain sections of WT and sEH KO mice (G) following sham surgery, and at (H) 1 day, (I) 4 days and (J) 28 days post-TBI. Analysis of lesion volumes demonstrated that deletion of sEH significantly reduced contusion volume and hemispheric enlargement at both 1 and 4 days, and significantly reduced contusion volume and preserved brain tissue at 28 days. The scale bar is $2 \mathrm{~mm}$. Values are mean \pm S.E.M $; * P<0.05,{ }^{*} P<0.01$ and $* * * P<0.001 \mathrm{vs}$. WT group ( $\mathrm{n}=12$ mice / group for behavior tests, repeated measures two-way ANOVA; $\mathrm{n}=7$ mice / group for histology, Student's $t$-test). 

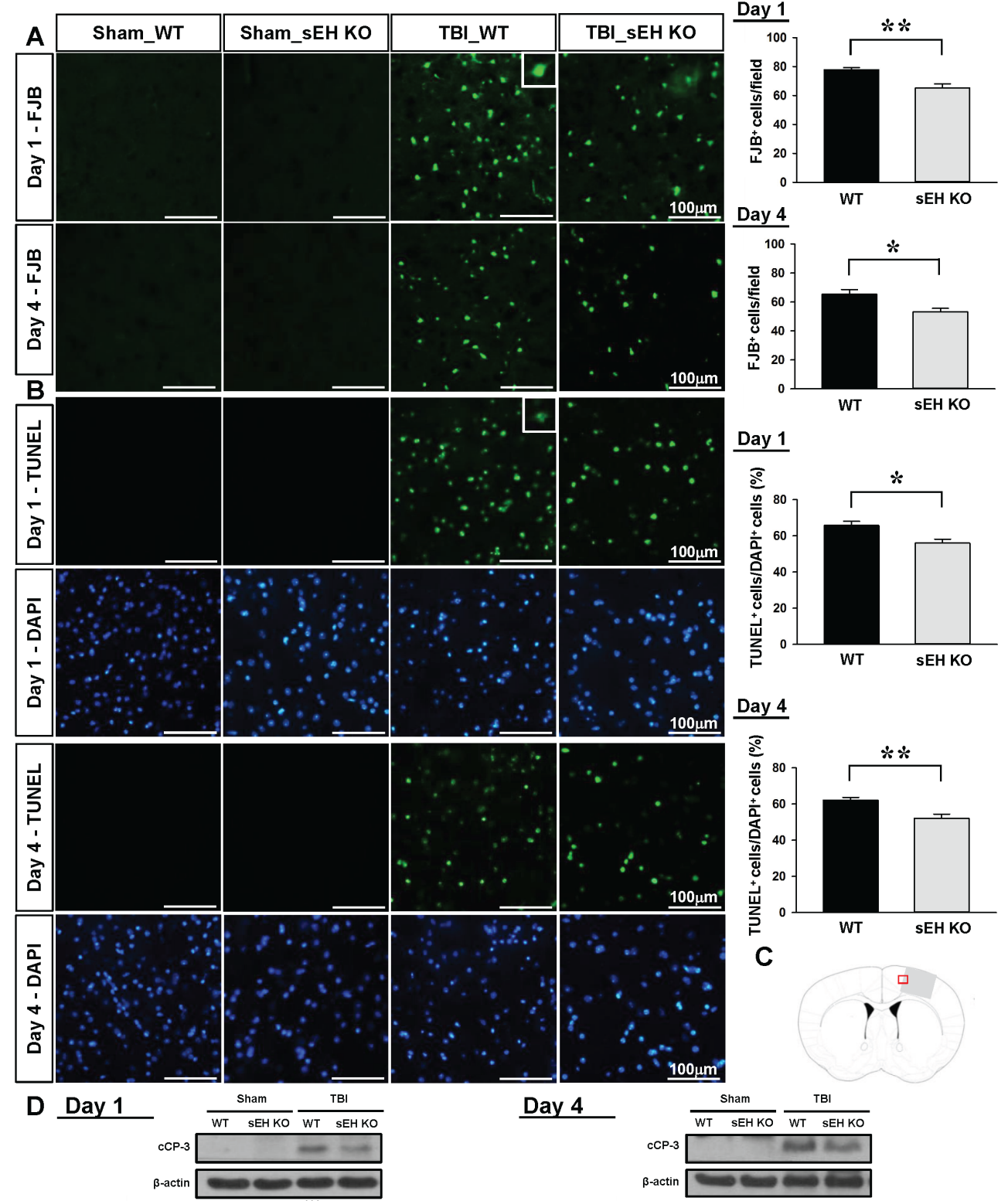

Day 4

\section{Day 4}

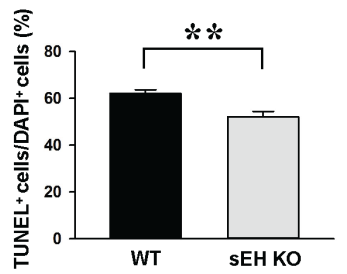

C
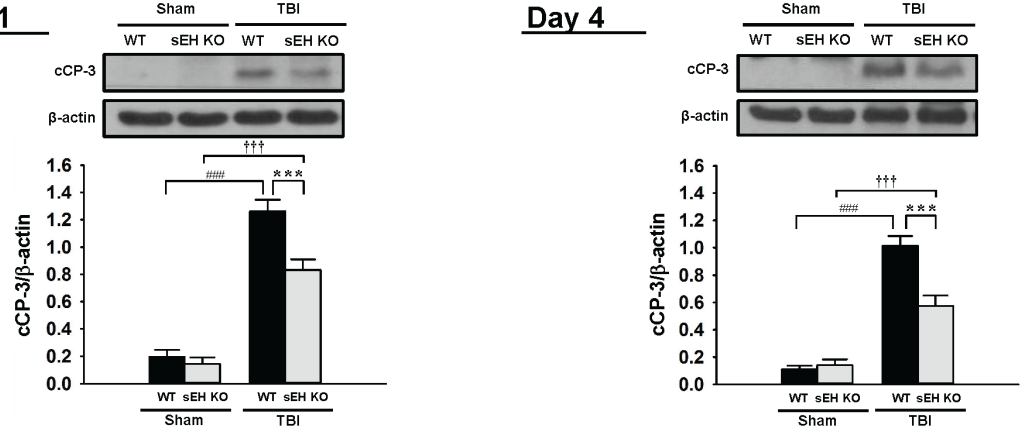

Figure 3: Deletion of $\mathbf{S E H}$ reduced neuronal damage and apoptotic cell death in mice after TBI. (A) Representative FJB, and (B) TUNEL (green) and DAPI-stained (blue) brain sections of WT and sEH KO mice at 1 and 4 days post-TBI. The inset is a representative FJB-positive or TUNEL-positive cell at higher magnification. Quantification analysis indicates that $\mathrm{sEH}$ KO mice had significantly fewer degenerating neurons and a lower percentage of TUNEL-positive cells than WT mice at both 1 and 4 days post-TBI. The total number of FJB-positive cells is expressed as the mean number per field of view $\left(0.8 \mathrm{~mm}^{2}\right)$. The percentage of TUNEL-positive cells is expressed as the percentage of nuclei that were stained by the TUNEL method/the total number of DAPI-stained nuclei. Sections were stained with DAPI (blue) to show all nuclei. (C) Brain atlas coronal brain section of a core injury region at $0.74 \mathrm{~mm}$ from the bregma. The red box indicates the the location of representative images. The scale bar is $100 \mu \mathrm{m}$. (D) Western blot analysis of cleaved caspase- 3 in the ipsilateral hemisphere of WT and sEH KO mice at 1 and 4 days following sham surgery or TBI. Deletion ofsEH significantly decreased the cleaved caspase-3 level at both 1 and 4 days post-TBI. cCP-3: cleaved caspase-3. Values are mean \pm S.E.M; ${ }^{\# \#, ~}{ }^{\dagger \dagger} P<0.001$ vs. sham group; $* P<0.05, * * P<0.01, * * * P<0.001$ vs. WT group $(\mathrm{n}=7$ mice / group, Student's $t$-test for histology and repeated measures twoway ANOVA for Western blots). 

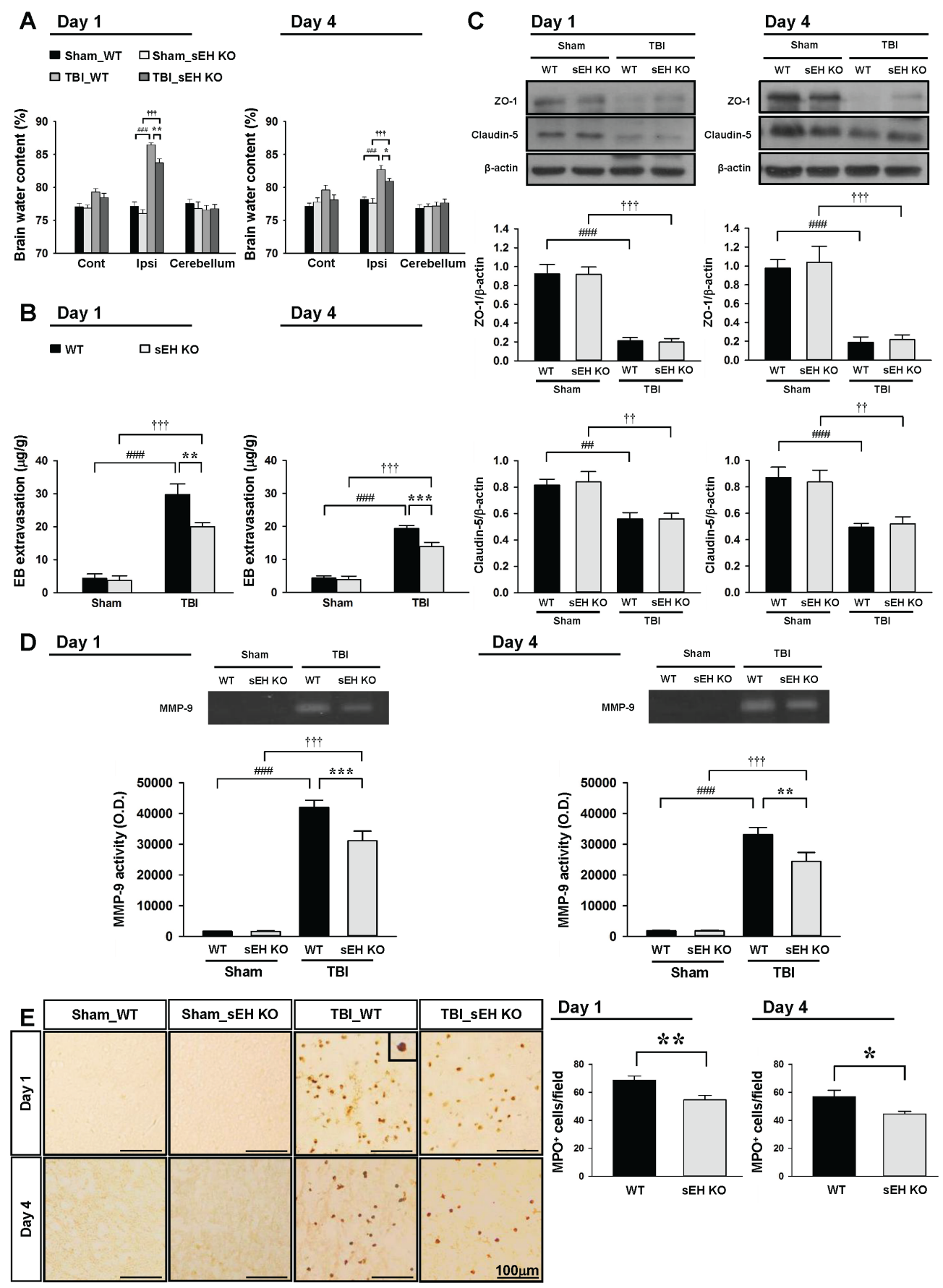

Figure 4: Deletion of SEH attenuates brain edema, BBB permeability, MMP-9 enzymatic activity and neutrophil infiltration after TBI. Deletion of sEH significantly decreased (A) brain water content and (B) leakage of Evans blue into the brain and in the ipsilateral hemisphere compared with the WT mice. Cont: contralateral cortex; Ipsi: ipsilateral cortex. (C) Western blot analysis of ZO-1 and claudin-5 in the ipsilateral hemisphere of WT and sEH KO mice at 1 and 4 days following sham surgery or TBI. Deletion of sEH did not affect TBI-mediated reduced expression of ZO-1 or claudin-5 at any tested time-points. (D) Representative zymography of MMP-9 activity from WT and sEH KO mice at 1 and 4 days following sham surgery or TBI. The gelatinase activity of MMP-9 was significantly decreased in sEH KO mice compared with WT control at both 1 and 4 days post-TBI. (E) Representative MPO-stained brain images of WT and sEH KO mice in the contusion margin (see the red box in the brain atlas coronal brain section in Figure 3C) at 1 day and 4 days following sham surgery or TBI. The inset is a representative MPO-positive cell at higher magnification. Cell count analysis shows that sEH KO mice had significantly fewer infiltrating neutrophils than WT control in the cortical contusion margin at 1 and 4 days post-TBI. The number of MPO-positive cells is expressed as the mean number per field of view $\left(0.8 \mathrm{~mm}^{2}\right)$. The scale bar is $100 \mu \mathrm{m}$. Values are mean \pm

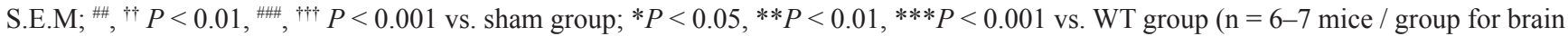
water content and Evans blue amount, and $\mathrm{n}=6$ mice / group for Western blot analysis and MMP-9 activity, repeated measures two-way ANOVA; $\mathrm{n}=6$ mice / group for MPO staining, Student's $t$-test). 
point. We next investigated matrix metalloproteinase (MMP)-9 activity and the degree of neutrophil infiltration, both of which contribute to BBB breakdown and brain edema [24]. MMP-9 is an endopeptidase and functions to degrade the extracellular matrix, including major components of the endothelial basal lamina, which is essential in maintaining BBB integrity [24]. MMP-9 activity was significantly increased in both WT mouse and sEH KO mouse injured brains at 1 and 4 days postTBI (all $p<0.001$; Figure 4D). In sEH KO mice, MMP-9 activity was significantly decreased compared with WT mice at both tested time-points (both $p<0.01$; Figure 4D). Moreover, TBI induced robust infiltration of neutrophils in both WT and sEH KO mice (Figure 4E). There were significantly fewer neutrophils in the in the contusion margin of sEH KO mouse brains compared with WT mouse brains at both 1 day $(54.6 \pm 3.1$ vs. $68.7 \pm 2.9$ cells/ field, $P=0.0082$; Figure 4E) and 4 days $(44.4 \pm 2.0 \mathrm{vs}$. $56.8 \pm 4.6$ cells/field, $P=0.0347$; Figure $4 \mathrm{E}$ ) post-TBI.

\section{Deletion of $\mathrm{sEH}$ reduces proinflammatory $\mathrm{M1}$ microglia/macrophage activation and heightens anti-inflammatory M2 microglia/macrophage response, and attenuates EET degradation after TBI}

We further assessed whether sEH deletion affected microglial activation and the expression of inflammatory mediators, both of which are key inflammatory processes following TBI. Activated microglia/macrophages were observed within the injured cortex at both 1 and 4 days, and the number of activated microglia/macrophages was significantly reduced in $\mathrm{sEH}$ mice compared with WT mice at 1 day $(36.9 \pm 1.9$ vs. $49.1 \pm 2.0$ cells/field, $P=0.0014$; Figure 5A) and 4 days $(32.8 \pm 2.0$ vs. 43.7 \pm 2.4 cells/field, $P=0.001$; Figure $5 \mathrm{~A}$ ). With regard to inflammatory mediators, TBI induced increases in IL$1 \beta$, IL-6, MIP-2, and MCP-1 protein expression levels in both WT and sEH KO mice at 1 and 4 days (Figures 5B$5 \mathrm{E})$. The injured hemispheres of $\mathrm{sEH} \mathrm{KO}$ mice exhibited significantly reduced IL-1 $\beta$, IL-6, MIP-2, and MCP-1 protein levels compared with WT mice at 1 day (IL-1 $\beta$ : $50.6 \pm 4.2$ vs. $72.7 \pm 6.1 \mathrm{pg} / \mathrm{mg}$ protein, $P<0.001$; Figure 5B; IL-6: $89.6 \pm 9.2$ vs. $130.0 \pm 7.4 \mathrm{pg} / \mathrm{mg}$ protein, $P<$ 0.001; Figure 5C; MIP-2: $215.7 \pm 18.3$ vs. $294.0 \pm 9.5$ $\mathrm{pg} / \mathrm{mg}$ protein, $P<0.001$; Figure 5D; MCP-1: $159.6 \pm$ 14.2 vs. $210.1 \pm 10.4 \mathrm{pg} / \mathrm{mg}$ protein, $P<0.001$; Figure $5 \mathrm{E})$ and 4 days (IL-1 $\beta$ : $44.0 \pm 4.3$ vs. $59.0 \pm 4.0 \mathrm{pg} / \mathrm{mg}$ protein, $P=0.002$; Figure 5B; IL-6: $49.8 \pm 5.0$ vs. 78.0 $\pm 4.5 \mathrm{pg} / \mathrm{mg}$ protein, $P<0.001$; Figure $5 \mathrm{C}$; MIP-2: 140.0 \pm 11.6 vs. $191.9 \pm 13.9 \mathrm{pg} / \mathrm{mg}$ protein, $P<0.001$; Figure 5D; MCP-1: $87.3 \pm 5.9$ vs. $125.8 \pm 12.3 \mathrm{pg} / \mathrm{mg}$ protein, $P$ $<0.001$; Figure 5E). In addition, TBI induced reductions in EET level and EET/14,15-DHET ratio, and an increase in 14,15-DHET level in WT mice at both 1 day and 4 days post-injury (all $P<0.05$; Figures 5F). Deletion of
sEH gene caused a significant elevation of EET level $(P$ $<0.001$ for both 1 day and 4 days) and EET/14,15-DHET ratio ( $P<0.001$ for 1 day and $P=0.042$ for 4 days), and a decrease of 14,15-DHET level $(P<0.001$ for both 1 day and 4 days; Figure $5 \mathrm{G}$ ) at both tested time-points.

Microglial and macrophage activation involves diverse phenotypes with different physiological roles that have been historically classified as a classically activated, proinflammatory M1 phenotype or an alternatively activated, anti-inflammatory M2 phenotype $[26,27]$. We next investigated whether sEH deletion affected the polarization of microglia/macrophages, using double-immunofluorescent staining with the microglia/macrophage marker Iba1 and with the marker of classically activated M1 microglia/macrophages (CD16/32) or alternatively activated M2 microglia/ macrophages (CD206, arginase 1). While no CD16/32positive microglia/ macrophages were observed in shamoperated brains (Supplementary Figure 2), CCI induced an increase of CD16/32-positive microglia/ macrophages in the contusion margin at both 1 and 4 days (Figure 6A). The CD16/32-Iba1 double-positive signal in the contusion margin was significantly decreased following sEH deletion at both 1 day $(P=0.035)$ and 4 days $(P=0.044$; Figure 6A). For M2 markers, CD206- or arginase 1-positive microglia/ macrophages were not detectable in shamoperated brains but were detectable at both 1 day and 4 days after injury. Genetic deletion of sEH resulted in a significant increase of M2 microglia/macrophages CD206Iba1 and arginase 1-Iba1 double-positive signals at 4 days post-injury in the contusion margin, emphasizing the antiinflammatory role of sEH deletion $(P=0.007$ for CD206 and $P<0.001$ for arginase 1; Figure 6A). IL-4 induces alternative $\mathrm{M} 2$ activation in microglia and macrophages [28]. We therefore sought to assess whether sEH deletion influenced IL-4 expression. Consistent with the CD206 and arginase 1 immunoreactivity results, the M2polarizing cytokine IL-4 level was significantly increased following sEH deletion at 4 days post-injury $(427.6 \pm 26.5$ versus $307.4 \pm 17.2 \mathrm{pg} / \mathrm{mg}$ protein, $P<0.001$; Figure 6B). Thus, sEH involvement in the regulation of inflammatory response may be crucial in the development of brain damage following TBI.

\section{Pharmacological inhibition of SEH by AUDA ameliorates brain edema, apoptosis, and reduces neuroinflammation after TBI}

To further investigate whether pharmacological inhibition also provided protection against TBI, we treated WT mice with intracerebroventricular (i.c.v.) injection of the $\mathrm{sEH}$ inhibitor AUDA (10uM) for four consecutive days following CCI (Figure 7A). We chose the route of i.c.v. administration to focus on the central $\mathrm{sEH}$ inhibition effects. Consistent with the responses of sEH KO mice, AUDA treatment significantly reduced brain water content 

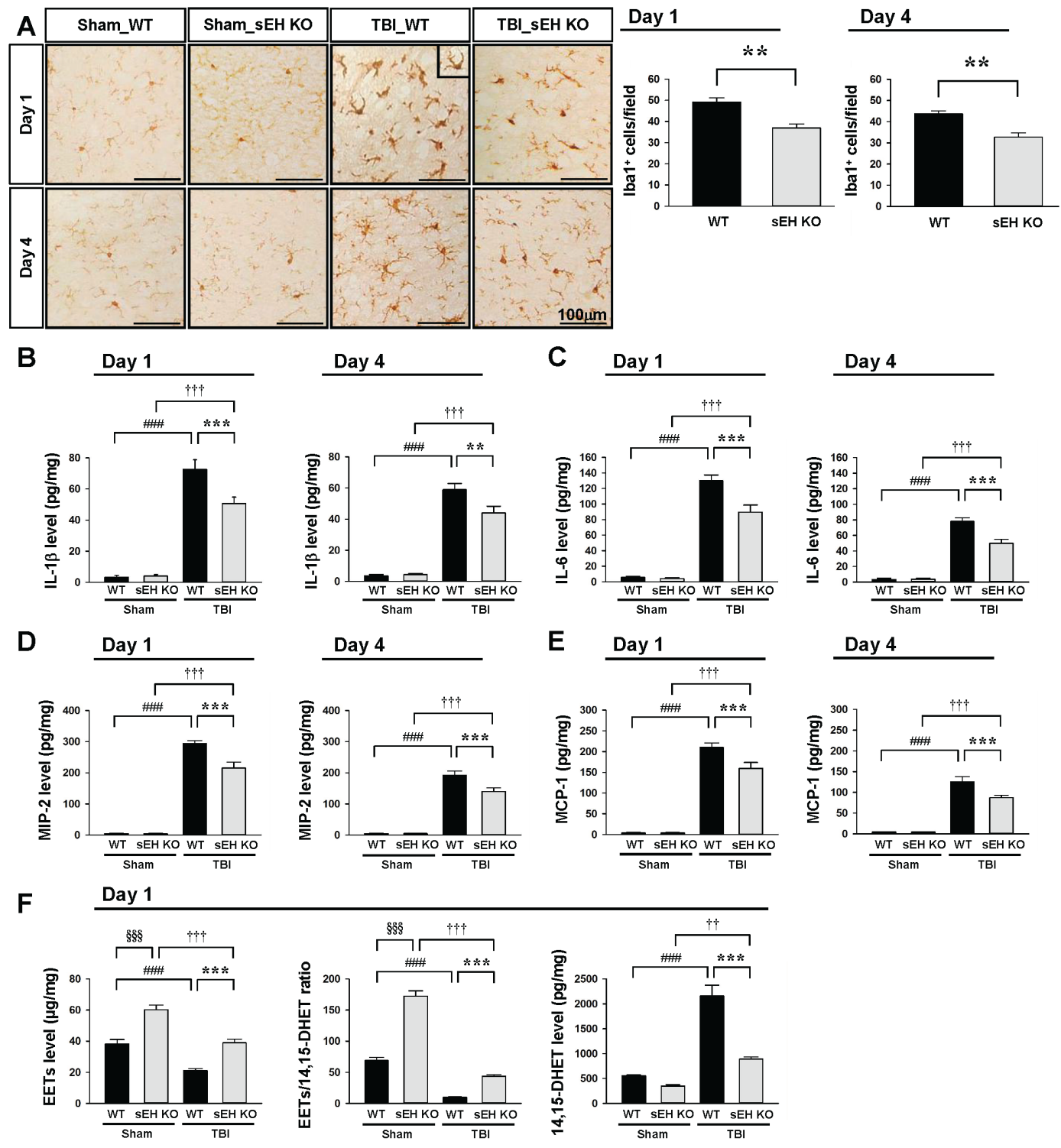

$\mathbf{F}$

Day 4
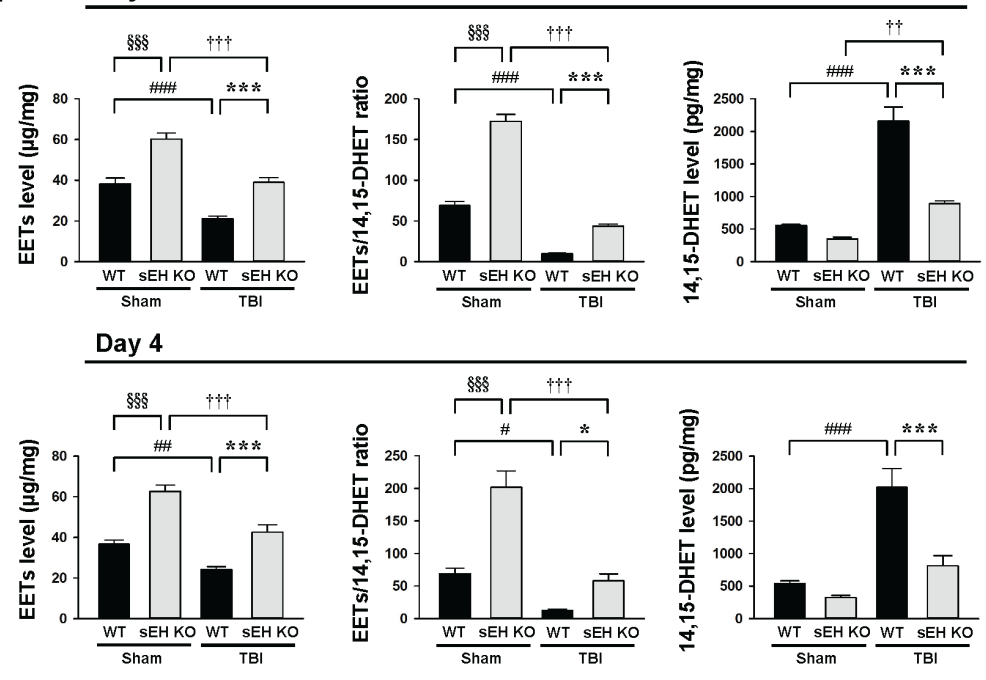

Figure 5: Deletion of sEH reduced microglial/macrophage activation and expression of inflammatory cytokines and chemokines and EET degradation. Representative (A) Iba1-stained images from WT and SEH KO mice in the contusion margin (see the red box in the brain atlas coronal brain section in Figure 3C) at 1 day and 4 days following sham surgery or TBI. Cell count analysis shows that sEH KO mice had significantly fewer Iba1-positive cells than WT in the cortical contusion margin at both 1 and 4 days postTBI. The number of Iba1-positive cells is expressed as the mean number per field of view $\left(0.8 \mathrm{~mm}^{2}\right)$. The scale bar is $100 \mu \mathrm{m}$. Bar graphs demonstrating (B) IL-1 $\beta$, (C) IL-6, (D) MIP-2, (E) MCP-1, (F) EET level, EET/14,15 DHET ratio and 14,15 DHET protein level, as assessed by ELISA in the ipsilateral cortices of WT and sEH KO mice at 1 day or 4 days following sham surgery or TBI. Deletion of sEH significantly attenuated IL-1 $\beta$, IL-6, MIP-2, and MCP-1 protein levels compared with WT mice at 1 day and 4 days post-TBI. sEH KO mice exhibited significantly increased EETs level, elevated EET/ 14,15 DHET ratio and reduced 14,15 DHET level compared with WT mice at both 1 day and 4 days post-TBI. Values are mean \pm S.E.M; ${ }^{\dagger} P<0.05,{ }^{\#} P<0.01,{ }^{\# \#, ~}{ }^{\dagger \dagger} P<0.001$ vs. sham group; ${ }^{*} P<0.05,{ }^{* * *}, 8 \$ \$ P<$ 0.001 vs. WT group ( $\mathrm{n}=6-7$ mice / group for cytokines and chemokines, and $\mathrm{n}=4-5$ mice / group for EETs and 14, 15 DHET, repeated measures two-way ANOVA). 


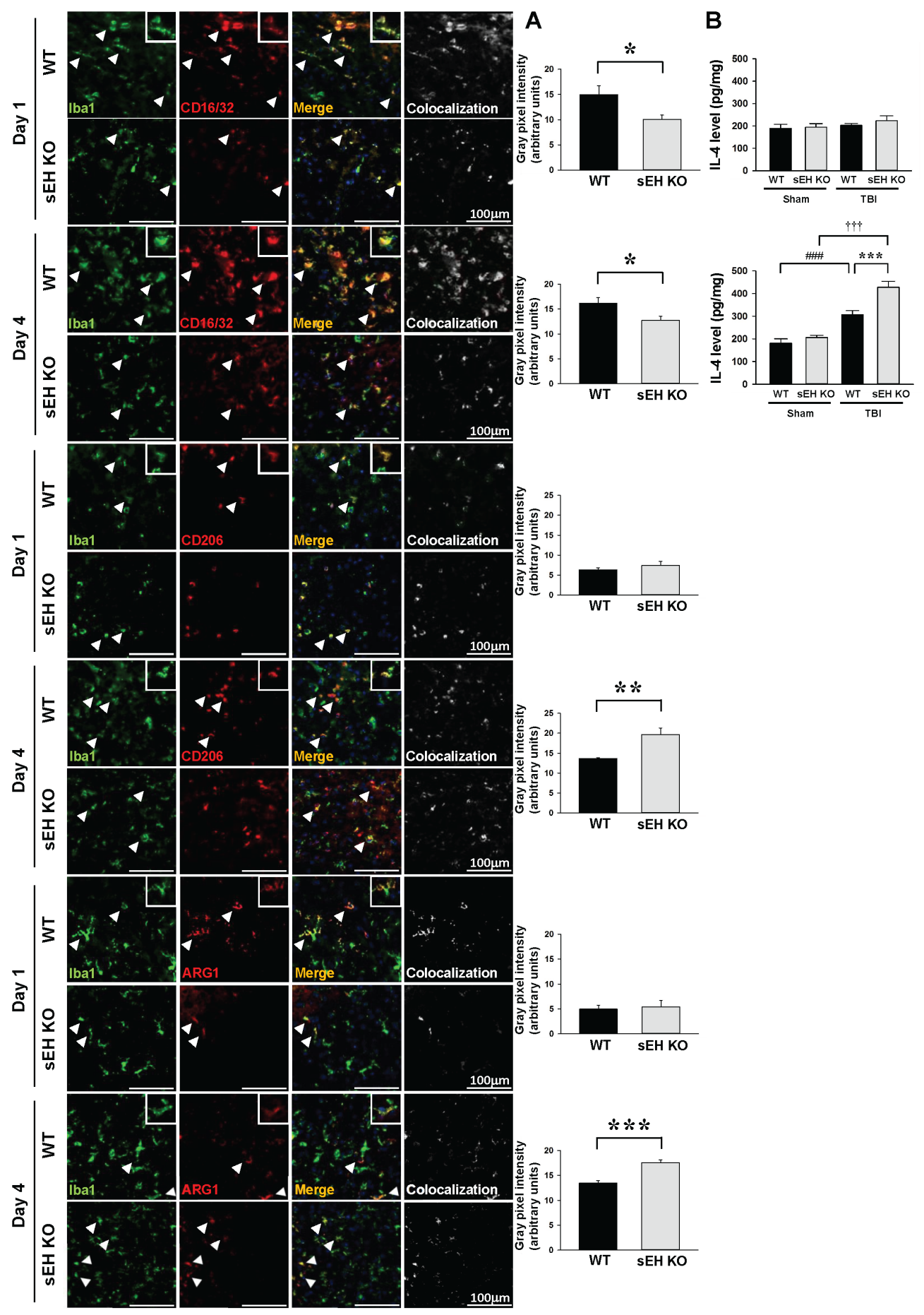

Figure 6: Deletion of $\mathbf{s E H}$ reduced proinflammatory microglia/macrophage activation and heightened antiinflammatory microglia/macrophage response after TBI. (A) Representative double-immunofluorescence of CD16/32 (classical activation marker; red), CD206 or arginase 1 (ARG1, alternative activation markers; red) and Iba1 (green) in the contusion margin (see the red box in the brain atlas coronal brain section in Figure 3C) of WT and sEH KO mice at 1 day and 4 days following TBI. Arrowheads indicate the cells of colocalization. The inset images represent higher magnification of the boxed region in the corresponding images. The scale bar is $100 \mu \mathrm{m}$. The bar graph shows the degree of Iba1 and CD16/32, CD206 or arginase 1 colocalization in gray pixel intensity. Deletion of sEH resulted in a significant decrease of CD16/32-Ibaldouble-positive signal at 1 day and 4 days and an increase of CD206Iba1 or arginase-1 double-positive signal at 4 days post-TBI. (B) Bar graphs of IL-4 protein level as assessed by ELISA in ipsilateral hemispheres of WT and sEH KO mice at 1 day and 4 days following sham surgery or TBI. Deletion of sEH caused a significant elevation of IL-4 level at 4 day. Values are mean \pm S.E.M; ${ }^{\# \#, ~}$, ${ }^{\dagger \dagger} P<0.001$ vs. sham group; ${ }^{*} P<0.05,{ }^{*} P<0.01,{ }^{* * *} P<0.001$ vs. WT group $(\mathrm{n}=$ 5 mice / group for CD16/32, CD 206 or arginase 1 and Iba1 double stainings, Student's $t$-test; $\mathrm{n}=6$ mice / group for IL-4 ELISA, repeated measures two-way ANOVA). 
$(81.8 \pm 0.5 \%$ vs. $84.2 \pm 0.3 \%, P=0.0017$; Figure $7 \mathrm{~B})$ and the cleaved caspase-3 level $(42.4 \%$ of the vehiclelevel, $P<0.001$; Figure $7 \mathrm{C}$ ) of the ipsilateral hemisphere compared with vehicle control treatment at 4 days postinjury. The MMP-9 activity was also significantly reduced following AUDA treatment $(P=0.023$; Figure 7D). Similarly, the expression of IL-1 $\beta$, IL-6 and MIP-2 was significantly decreased in the AUDA-treated injured brains compared with the vehicle group at 4 days (IL-1 $\beta$ : $66.4 \pm$ 3.1 vs. $86.0 \pm 5.1 \mathrm{pg} / \mathrm{mg}$ protein, $P=0.005$; IL-6: $74.3 \pm$ 5.1 vs. $113.2 \pm 12.0 \mathrm{pg} / \mathrm{mg}$ protein, $P=0.01$; MIP-2: 253.2 \pm 17.0 vs. $333.9 \pm 24.8 \mathrm{pg} / \mathrm{mg}$ protein, $P=0.02$; Figure 7E). Moreover, CCI induced reductions in EET level and EET/14,15-DHET ratio, and an increase in 14,15DHET level (all $P<0.01$; Figures $7 \mathrm{~F}$ ). In parallel with the findings in genetic deletion of sEH, AUDA treatment resulted in significantly elevated EET level $(P=0.003)$ and decreased EET/14,15-DHET ratio $(P<0.001)$, and reduced 14,15-DHET level $(P<0.001$; Figure $7 F)$. These findings indicate that pharmacological inhibition of $\mathrm{sEH}$ using AUDA resulted in a reduction of EET degradation, accompanied by attenuation of brain edema, apoptosis and inflammatory responses following TBI.

\section{Pharmacological inhibition or genetic deletion of SEH attenuated LPS- or interferon-gamma- induced proinflammatory responses in cultured microglia}

Our in vivo results demonstrated that both genetic deletion and pharmacological inhibition of sEH reduced brain damage and inflammatory responses after TBI. Thus, we further used mouse BV2 microglial cells and primary cultured microglia to investigate whether $\mathrm{sEH}$ directly modulated microglia-mediated neuroinflammation and to elucidate the underlying molecular mechanisms. Lipopolysaccharide (LPS), a strong immunostimulant, and interferon (IFN) $-\gamma$, a cytokine that is released following TBI [29], were used to activate microglia. To establish the role of microglial sEH in microglial activation, we first determined sEH protein expression. Both LPS (100 ng/ $\mathrm{mL})$ and interferon-gamma (IFN- $\gamma, 10 \mathrm{ng} / \mathrm{mL}$ ) treatment for $24 \mathrm{~h}$ induced significant increases in $\mathrm{sEH}$ protein levels (2-fold) in BV2 microglial cells (both $P<0.001$; Figure $8 \mathrm{~A})$. The exposure of BV2 microglia to LPS for $24 \mathrm{~h}$ markedly increased NO release in the culture supernatant, but co-treatment with $1,5,10$, or $50 \mu \mathrm{M}$ AUDA for 24 h significantly reduced LPS-induced NO production to $55 \%, 48 \%, 46 \%$ and $40 \%$ of that observed for the vehicle control group, respectively, and $10 \mu \mathrm{M}$ AUDA provided the highest degree of anti-inflammatory action (all $P<$ 0.001 ; Figure $8 \mathrm{~B}$ ). Therefore, the dosage of $10 \mu \mathrm{M}$ was employed for subsequent studies. We further used primary cultured microglia to confirm the effects of AUDA on microglial activation. Incubation with both LPS (100 ng/ $\mathrm{mL})$ and IFN- $\gamma(10 \mathrm{ng} / \mathrm{mL})$ for $24 \mathrm{~h}$ increased NO release in the culture supernatants and co-treatment with $10 \mu \mathrm{M}$ AUDA for $24 \mathrm{~h}$ significantly reduced LPS-induced NO production to $18 \%$ and IFN- $\gamma$-induced NO production to $46 \%$ of that observed for the vehicle control group(both $P<0.001$; Figure 8C). To confirm whether the protective effect of the sEH inhibition was attributed to increased EETs, we treated LPS- or IFN- $\gamma$ - stimulated primary microglia with $10 \mu \mathrm{M}$ AUDA in the presence or absence of the putative pan-EET receptor antagonist 14,15-EEZE $(1 \mu \mathrm{M}) .14,15$-EEZE did not affect the baseline NO level but the protective effect of AUDA on microglial activation was completely abolished by administration of 14,15-EEZE in both LPS- and IFN- $\gamma$ - stimulated primary microglia (Figures 8C), indicating that the salutary effect observed with sEH inhibition was specifically due to EETs. Next, we analyzed the effects of AUDA on release of the proinflammatory cytokines and chemokines, a key hallmark of microglial activation. IL-1 $\beta$, IL- 6 and MIP-2 levels were significantly increased in the culture media of LPS-stimulated primary microglia, and these increases were significantly decreased by treatment with $10 \mu \mathrm{M}$ AUDA (IL- $1 \beta$ : $11.1 \pm 0.7$ vs. $30.8 \pm 0.7 \mathrm{pg} / \mathrm{mg}, P<0.001$; IL-6: $11.6 \pm 0.3$ vs. $29.7 \pm 0.7 \mathrm{pg} / \mathrm{mg}, p<0.001$; MIP-2: $15.1 \pm 0.5$ vs. $32.6 \pm 0.5 \mathrm{pg} / \mathrm{mg}, p<0.001$, Figure 8D). We further investigated whether the lack of sEH would influence microglial activation by comparing IFN- $\gamma$ induced NO production using primary microglia derived from WT and sEH KO mice. When stimulated by $10 \mathrm{ng} /$ $\mathrm{mL}$ IFN- $\gamma$, NO release was significantly increased in the culture supernatants of both WT and sEH KO mice by 24 $\mathrm{h}$ (Figure 8E). Deletion of sEH significantly reduced IFN$\gamma$-induced NO production to $49 \%$ that observed for the WT group $(P<0.001$; Figure 8E), suggesting that sEH deletion suppressed IFN- $\gamma$-stimulated microglial activation.

As AUDA was found to inhibit NO production, we examined the effect of AUDA on inducible nitric oxide synthase (iNOS) protein expression. The iNOS protein levels were markedly up-regulated after 6 and $24 \mathrm{~h}$ of LPS or IFN- $\gamma$ treatment, and AUDA significantly attenuated iNOS protein expression in LPS-stimulated primary microglia at $6 \mathrm{~h}(69 \%$ of vehicle-level, $P=0.002)$ and $24 \mathrm{~h}$ (50\% of vehicle-level, $P=0.008)$ and in IFN- $\gamma$-stimulated primary microglia at $6 \mathrm{~h}(52 \%$ of vehicle-level, $P=0.007)$ and $24 \mathrm{~h}(62 \%$ of vehicle-level, $P=0.001)$, respectively (Supplementary Figure 3A \& Figure 8F). Collectively, these results support the notion that $\mathrm{sEH}$ functions as an important regulator of microglial activation.

We next investigated whether AUDA influenced the activation of mitogen-activated protein kinases (MAPKs)$\mathrm{NF}-\kappa \mathrm{B}$, a major signaling pathway that induces a variety of proinflammation mediators in microglia during acute brain injury [30]. Activation of $\mathrm{NF}-\kappa \mathrm{B}$, as indicated by phosphorylation of $\mathrm{P} 65$ at serine 536, was observed at 1 and $2 \mathrm{~h}$ following LPS or IFN- $\gamma$ stimulation (all $P<0.01$; Supplementary Figure 3B \& Figure 8G). Co-treatment with $10 \mu \mathrm{M}$ AUDA significantly attenuated the LPS- 
induced increased levels of p-P65 Ser536 at $1 \mathrm{~h}(69 \%$ of vehicle-level, $P=0.002)$ and $2 \mathrm{~h}(73 \%$ of vehicle-level, $P<0.001)$, and the IFN- $\gamma$-induced increased levels of p-P65 Ser536 at $1 \mathrm{~h}(69 \%$ of vehicle-level, $P=0.014)$ and $2 \mathrm{~h}(73 \%$ of vehicle-level, $P=0.001)$ (Supplementary Figure $3 \mathrm{~B} \&$ Figure $8 \mathrm{G})$. Next, we evaluated the inhibitory effects of AUDA on LPS- or IFN- $\gamma$-induced activation of MAPKs, including P38, jun amino-terminal kinases (JNK) and extracellular signal-regulated kinases p44/42 (ERK). Stimulation of microglia with both LPS and IFN- $\gamma$ for 1 and $2 \mathrm{~h}$ resulted in rapid activation of P38, JNK and ERK. Co-treatment with $10 \mu \mathrm{M}$ AUDA significantly
A

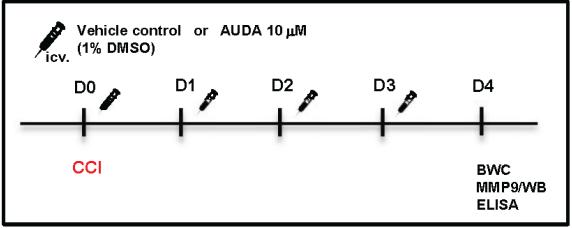

B

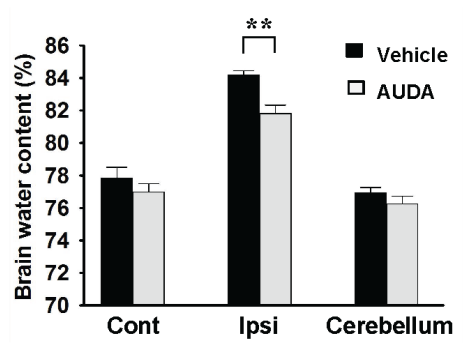

E

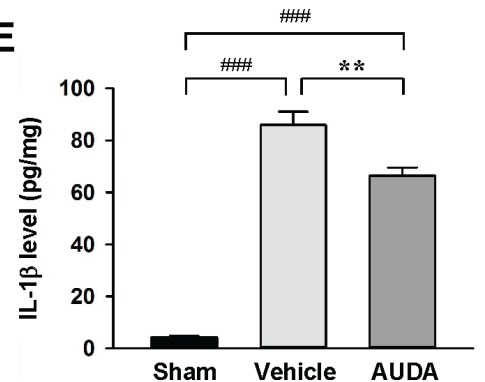

$\mathbf{F}$

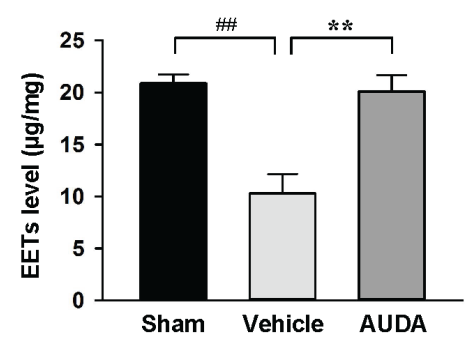

C
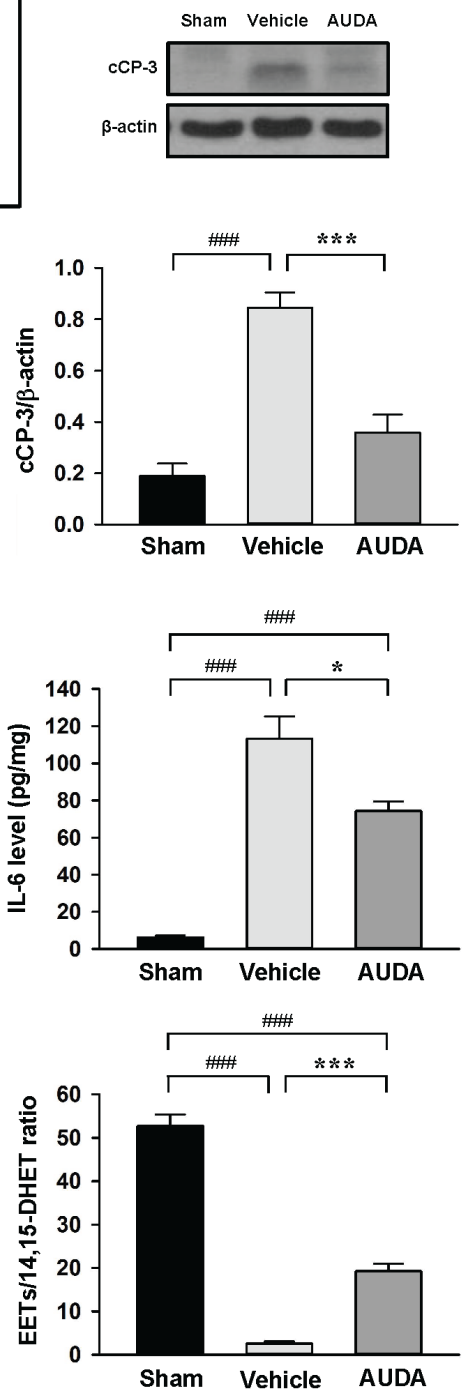

D
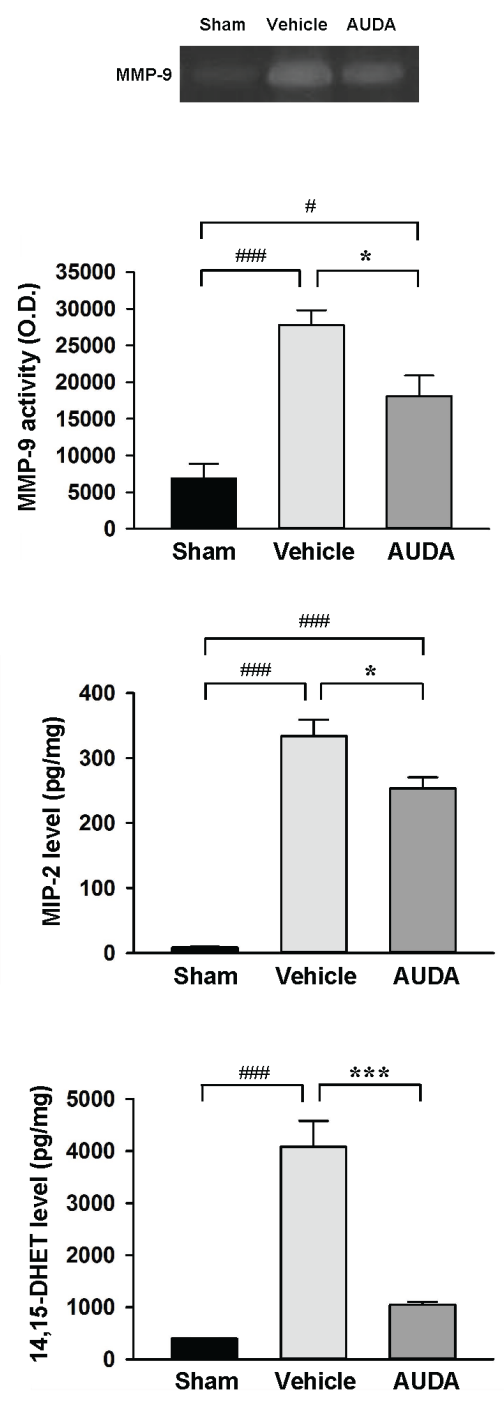

Figure 7: Intracerebroventricular administration of AUDA reduced brain edema, apoptosis, MMP-9 activity, and expression of inflammatory cytokines and chemokines and EET degradation after TBI. (A) Experimental design and animal groups classification. TBI: traumatic brain injury; BWC: brain water content; MMP-9: matrix metalloproteinase-9; WB: Western blots; ELISA: enzyme-linked immunosorbent assay. (B) AUDA significantly decreased brain water content in the ipsilateral hemisphere compared with the WT mice. Cont: contralateral cortex; Ipsi: ipsilateral cortex. (C) Western blot analysis of cleaved caspase-3 and (D) MMP-9 activity in the ipsilateral hemisphere of sham-injured, vehicle-treated and AUDA-treated mice at 4 days following injury. AUDA treatment significantly decreased the cleaved caspase-3 level and MMP-9 activity at 4 days post-TBI. cCP-3: cleaved caspase-3. Bar graphs demonstrating (E) IL-1 $\beta$, IL-6, MIP-2 levels and (F) EET level, EET/14,15 DHET ratio and 14,15 DHET protein level, as assessed by ELISA in the ipsilateral cortices of WT at 4 days following sham surgery or TBI. AUDA significantly attenuated IL-1 $\beta$, IL-6, and MIP-2 protein levels compared with WT mice at 4 days post-injury. AUDA-treated mice exhibited significantly increased EETs level, elevated EET/ 14,15 DHET ratio, and reduced 14,15 DHET level compared with vehicle-treated mice at 4 days post-TBI. Values are mean \pm S.E.M; ${ }^{\#} P<0.05,{ }^{\#} P<0.01,{ }^{\# \#} P<0.001$ vs. sham group; ${ }^{*} P<0.05,{ }^{*} P<0.01, * * * P<0.001$ vs. vehicle group ( $\mathrm{n}=7$ mice / group for brain water content, $\mathrm{n}=5-7$ mice / group for Western blot analysis, MMP-9 activity, cytokines and chemokines, and $\mathrm{n}=4 \mathrm{mice} /$ group for EETs and 14, 15 DHET, one-way ANOVA). 

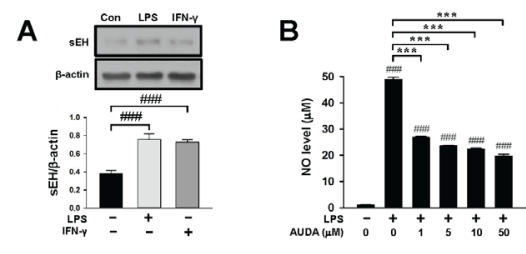

D

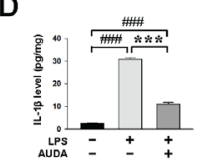

$F_{6 h}$

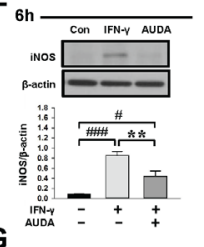

G
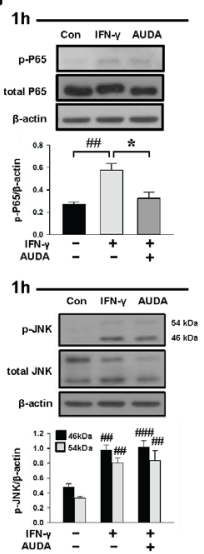

H

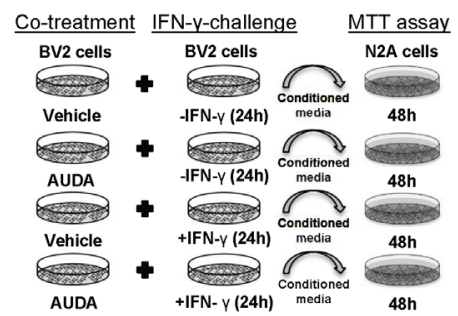

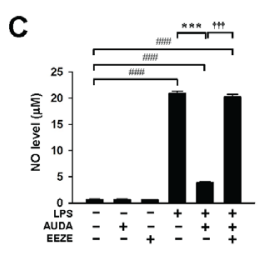
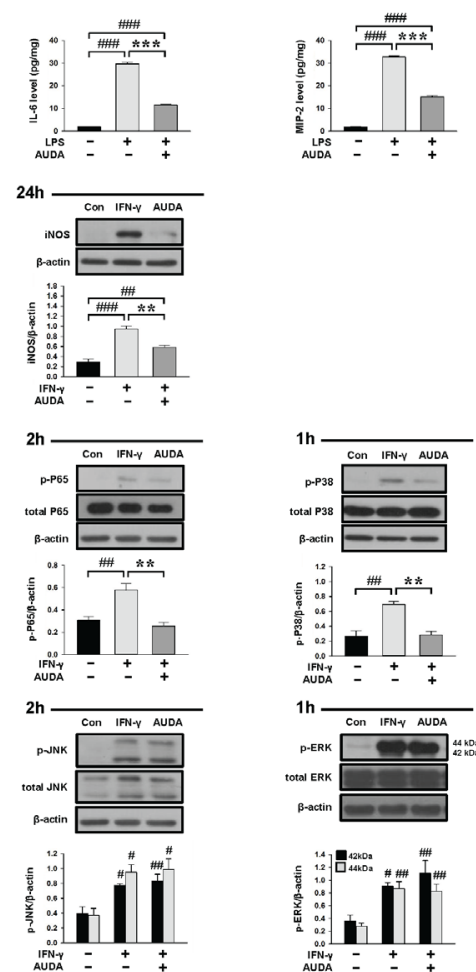

MTT assay
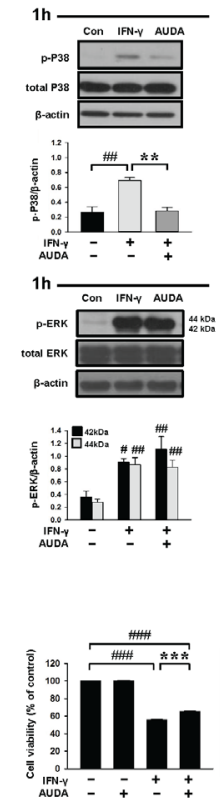

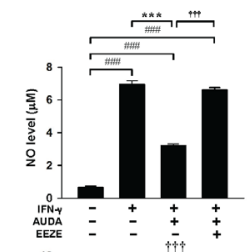

E
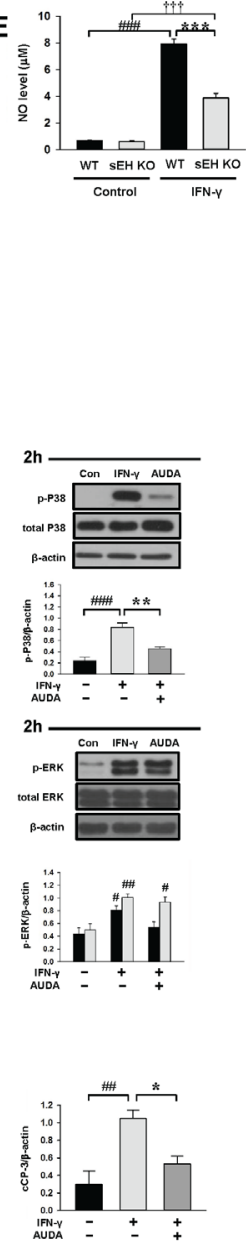

Figure 8: Pharmacological inhibition or genetic deletion of sEH inhibited LPS- or IFN- $\gamma$-induced inflammatory responses in cultured microglia. (A) In BV2 microglia, both LPS and IFN- $\gamma$ treatment for $24 \mathrm{~h}$ induced a significant increase of sEH

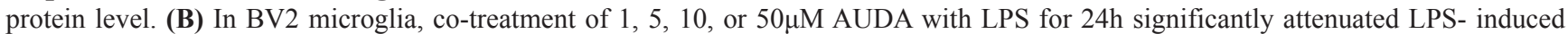

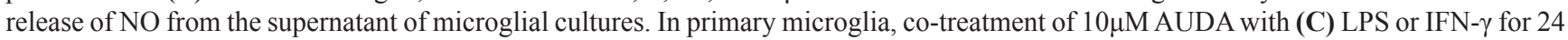
$\mathrm{h}$ significantly reduced LPS- or IFN- $\gamma$-induced release of NO from the supernatants of microglial cultures. The protective effect of AUDA on microglial activation was completely abolished by administration of the putative pan-EET receptor antagonist 14,15-EEZE $(1 \mu \mathrm{M})$

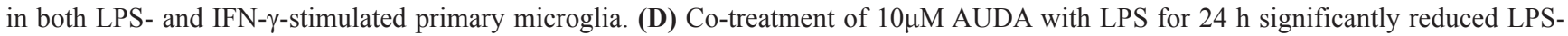
induced release of IL-1 $\beta$, IL-6 and MIP-2 from the supernatants of primary microglial cultures. (E) In primary mouse microglial cultures, deletion of sEH significantly attenuated IFN- $\gamma$-induced release of NO from the supernatant of microglial cultures. (F) Representative immunoblots and bar graphs show that co-treatment of $10 \mu \mathrm{M}$ AUDA with IFN- $\gamma$ significantly reduced iNOS protein levels at $6 \mathrm{~h}$ and $24 \mathrm{~h}$. (G) Representative immunoblots and bar graphs show that co-treatment of 10 $\mu \mathrm{M}$ AUDA with IFN- $\gamma$ significantly reduced IFN- $\gamma$-induced P65 and P38 phosphorylation at $1 \mathrm{~h}$ and $2 \mathrm{~h}$, but did not affect JNK or ERK phosphorylation in primary microglia. (H) Experimental scheme of neuronal survival in N2A cells in response to IFN- $\gamma$-treated BV2-conditioned media with or without AUDA pretreatment. BV2 microglia

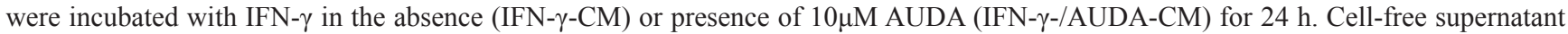
fractions were applied to N2A cells for $48 \mathrm{~h}$ to evaluate the changes in cell viability and cleaved caspase- 3 level. Neuronal cell death increased after exposure to IFN- $\gamma$-treated conditioned microglial media; the effect was significantly reduced by microglia pretreatment with $10 \mu \mathrm{M}$ AUDA. Western blot analysis showed that AUDA significantly reduced the cleaved caspase-3 level compared with N2A cells treated with conditioned microglia media alone. cCP-3: cleaved caspase-3. Values are presented as mean \pm S.E.M of four independent experiments. ${ }^{\#} P<0.05,{ }^{\#} P<0.01,{ }^{\# \#, ~}{ }^{\$} \$ \$ P<0.001$ vs. normal control; ${ }^{*} P<0.05,{ }^{*} P<0.01,{ }^{* * *} P<0.001$ vs. $\mathrm{LPS} / \mathrm{IFN}-\gamma$ stimulation alone or WT group (one way ANOVA for pharmacological experiments and two-way ANOVA for gene deletion experiment). 
reduced LPS-induced P38 phosphorylation at $1 \mathrm{~h}(69 \%$ of vehicle-level, $P<0.001)$ and $2 \mathrm{~h}(73 \%$ of vehicle-level, $P=0.011)$, and IFN- $\gamma$-induced P38 phosphorylation at $1 \mathrm{~h}(69 \%$ of vehicle-level, $P=0.002)$ and $2 \mathrm{~h}(73 \%$ of vehicle-level, $P=0.005$ ) (Supplementary Figure 3B \& Figure $8 \mathrm{G})$. However, ERK and JNK phosphorylation was not affected (all $P>0.05$; Supplementary Figure 3B \& Figure 8G). Similarly, AUDA significantly attenuated immunoreactivity for $\operatorname{iNOS}(P=0.018)$ at 24 h, phospho-P65 $(P=0.002)$, phospho-P38 $(P=0.007)$ at $2 \mathrm{~h}$ but had no effect on phospho-JNK or phospho-ERK p44/42 at $2 \mathrm{~h}$ following IFN- $\gamma$ stimulation in primary microglia (Figure 9). Together, these results suggest that AUDA suppress the P38 signaling pathway and NF$\kappa \mathrm{B}$ activation, resulting in the inhibition of microglial activation and proinflammatory responses.

Activated microglia are thought to contribute to delayed neuronal death after TBI by releasing neurotoxic mediators [6]. Accordingly, we further investigated whether inhibition of $\mathrm{sEH}$ in microglia conferred protection against microglial-induced neuronal injury by measuring the viability of N2A cells exposed to LPStreated or IFN- $\gamma$-treated conditioned media from BV2 microglia for 2 days in the presence or absence of AUDA (Supplementary Figure 3C \& Figure 8H). Conditioned media from LPS-stimulated microglia (LPS-CM) or IFN- $\gamma$-stimulated microglia (IFN- $\gamma-\mathrm{CM}$ ) significantly decreased N2A cell viability to $53.4 \pm 0.5 \%(p<0.001)$ or $55.5 \pm 0.5 \%(p<0.001)$ of the control-level, respectively. However, the viability of N2A cells stimulated with LPS-treated (LPS/AUDA-CM) or IFN- $\gamma$-treated (IFN- $\gamma$ / AUDA-CM) conditioned microglia media from the $10 \mu \mathrm{M}$ AUDA treatment group markedly increased to $62.4 \pm 0.8 \%(p<0.001)$ and $65.2 \pm 0.2 \%(p<0.001)$, respectively (Supplementary Figure $3 \mathrm{C} \&$ Figure $8 \mathrm{H}$ ). The cleaved caspase-3 levels in N2A cells treated with LPS/ AUDA-CM or IFN- $\gamma$-/AUDA-CM were also significantly decreased to $40.2 \%(P=0.035)$ or $50.7 \%(P=0.037)$ of the vehicle-level, respectively (Supplementary Figure 3C $\&$ Figure $8 \mathrm{H}$ ). Taken together, these results indicate that the protective effect of AUDA on neuronal viability is at least partly conferred through the inhibition of microglialinduced injury.

\section{DISCUSSION}

In this study, we show that genetic deletion of $\mathrm{sEH}$ improved long-term behavioral outcomes and attenuated brain edema in mice subjected to TBI. Brain tissue damage, apoptosis, and BBB disruption were also reduced in sEH KO mice. Mechanistically, sEH deletion reduced microglial/macrophage activation, neutrophil infiltration, protein expression of proinflammatory mediators and MMP-9 activity. Similar to sEH gene deletion, pharmacological inhibition of sEH using AUDA reduced brain edema, apoptosis and inflammatory responses in mouse TBI. In the in vitro studies, AUDA attenuated LPS-stimulated or IFN- $\gamma$-stimulated NO production in both primary microglia and the BV2 cell line, which was associated with reduced activation of P38 and NF- $\kappa$ B signaling in both LPS-stimulated and IFN- $\gamma$-stimulated primary microglia. Deletion of $\mathrm{sEH}$ also reduced IFN- $\gamma$ stimulated NO production in mouse primary microglia. Conditioned media from LPS-stimulated or IFN- $\gamma$ stimulatedBV2 cells caused death in N2A cells, but treating LPS-stimulated or IFN- $\gamma$-stimulatedBV2 cells with AUDA reduced neuronal cell death induced by microglial conditioned media. The current study extends upon previous findings of the protective effects of $\mathrm{sEH}$ inhibition on behavioral recovery following TBI in mice and provides new evidence of the role of microgliainduced inflammation in the neuroprotective effects of sEH inhibition in TBI.

We showed that TBI induced upregulation of $\mathrm{sEH}$ protein and that $\mathrm{sEH}$ was expressed in microglia in the injured brain. This was associated with a decrease in EET level and an increase in 14,15 DHET level. Our data also demonstrated upregulation of $\mathrm{sEH}$ protein expression levels in LPS- and IFN- $\gamma$-stimulated microglia, suggesting that inhibition of sEH would be beneficial because it likely increases and prolongs the functional effects of anti-inflammatory EETs in this proinflammatory condition following TBI. The sEH gene promoter region contains recognition sites for a number of transcription factors including $\mathrm{NF}-\kappa \mathrm{B}$ and activator protein [31], both of which respond to inflammation and are activated following TBI [32-34]. Indeed, our data are in line with previous studies showing an elevated cerebral $\mathrm{sEH}$ protein level in rodent models of brain damage including cerebral ischemia [12], Parkinsonism [16], and seizures [17]. We showed that TBI induced increased sEH expression at $1 \mathrm{~h}$. As previous studies have demonstrated that rodent TBI induced fast activation of $\mathrm{NF}-\kappa \mathrm{B}$ as early as $15 \mathrm{~min}$ [32] and increased c-fos and c-Jun mRNA expression (components of the AP-1 complex) at 5 min after injury $[33,34]$, it is possible that TBI-induced activation of NF- $\kappa \mathrm{B}$ and $\mathrm{AP}-1$ contributes to the early elevation in $\mathrm{sEH}$ expression.

Accumulating evidence has documented the effect of $\mathrm{sEH}$ inhibition in protection against various models of brain damage $[16,17,19,20]$. Both gene deletion and pharmacological inhibition of sEH also reduce functional and histological damage following experimental cerebral ischemia $[19,20]$. Although gene deletion of sEH reduced motor and working memory deficits caused by mouse TBI [21], it remains undetermined whether it attenuated the extent of neuronal damage, and the precise mechanisms of the protective effect have not been investigated. Thus, the current data confirm and extend upon previous reports showing a beneficial effect of $\mathrm{sEH}$ inactivation in improving long-term functional and histological outcomes following TBI. Specifically, we expand upon 


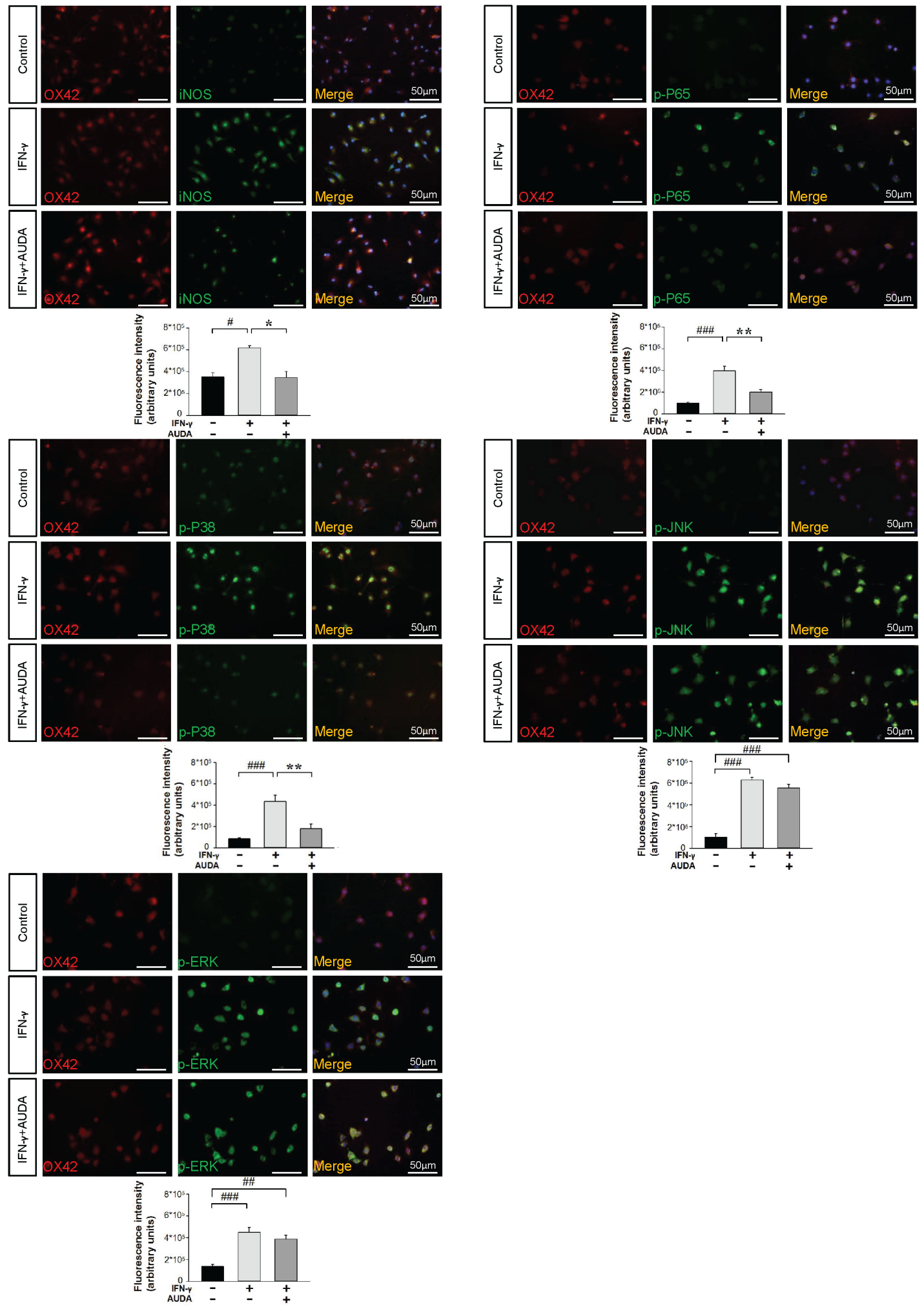

Figure 9: AUDA inhibited IFN- $\gamma$-induced iNOS expression and phosphorylation of P65 and P38 in primary microglia cultures. Immunolabeling of iNOS (green), phospho-P65 (green), phospho-P38 (green), phospho-JNK (green), phospho-ERK p44/42 (green) with OX42 (red), a marker of microglia. Co-localization is shown by yellow labeling. Cells were stained with DAPI (blue) to

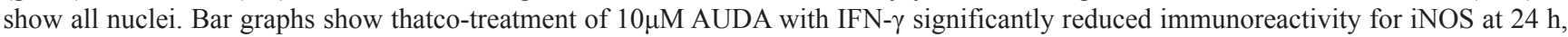
phospho-P65, phospho-P38 at $2 \mathrm{~h}$ but had no effect on phospho-JNK or phospho-ERK p44/42 immunoreactivity at $2 \mathrm{~h}$. Values are presented as mean \pm S.E.M of four independent experiments. ${ }^{\#} P<0.05,{ }^{\# \#} P<0.01,{ }^{\# \#} P<0.001$ vs. normal control; ${ }^{*} P<0.05, * * P<0.01$ vs. IFN- $\gamma$ stimulation alone (one-way ANOVA). The scale bar is $50 \mu \mathrm{m}$. 
previous findings by demonstrating that $\mathrm{sEH}$ inhibition reduced microglial activation and contributed to improved neuronal survival. We showed that the level of EETs and the ratio of EETs to 14,15-DHET in the injured brain were significantly increased in SEH KO mice and AUDAtreated mice and that administration of the 14,15-EET antagonist 14,15-EEZE abolished the anti-inflammatory effect of AUDA in cultured microglia, suggesting that the protection mediated by $\mathrm{sEH}$ inhibition is mainly due to augmenting endogenous 14,15-EET. Taken together, these data demonstrate that selectively increasing cerebral EET concentrations by sEH inhibition not only improved neurobehavioral outcomes but also reduced brain tissue damage following TBI in mice, thereby providing evidence in support of $\mathrm{sEH}$ inhibitors as a potential therapeutic intervention for neuroprotection after TBI.

Brain edema is one of the major prognostic factors following TBI and may cause increased intracranial pressure, decreased cerebral perfusion pressure and eventually reduced cerebral blood flow with impaired glucose and oxygen delivery to the brain tissue [5]. In the present study, we showed that both gene deletion and pharmacological inhibition of $\mathrm{sEH}$ attenuated brain edema, MMP-9 activity and the expression of cytokines and chemokines. Deletion of $\mathrm{sEH}$ also reduced BBB disruption, neutrophil infiltration, and microglial activation. Following TBI, microglial activation impairs $\mathrm{BBB}$ function and causes brain edema due to the release of various molecules including oxygen reactive species, proteolytic enzymes, and inflammatory cytokines [6, 24]. The increased levels of MMPs, particularly MMP9, disrupt the basal lamina proteins and degrade the tight junction complexes, also resulting in BBB breakdown [24]. In addition, excessive recruitment of neutrophils in the brain causes the release of inflammatory mediators and MMPs, which may further activate microglia, thus impairing $\mathrm{BBB}$ integrity and exacerbating brain edema formation [35]. Our results are in agreement with published data showing that deletion of the sEH gene reduced hydrocephalus, vascular inflammation and brain edema after experimental subarachnoid hemorrhage [36]. To clarify whether the effect of sEH inhibition on TBIinduced brain edema is reduced cerebral inflammation, we injected the sEH inhibitor, AUDA, directly into the lateral ventricle. The parallel results obtained with AUDA following i.c.v. administration were consistent with the results of the experiments in $\mathrm{SEH} \mathrm{KO}$ mice. Therefore, our results suggest that the protective effect on brain edema is

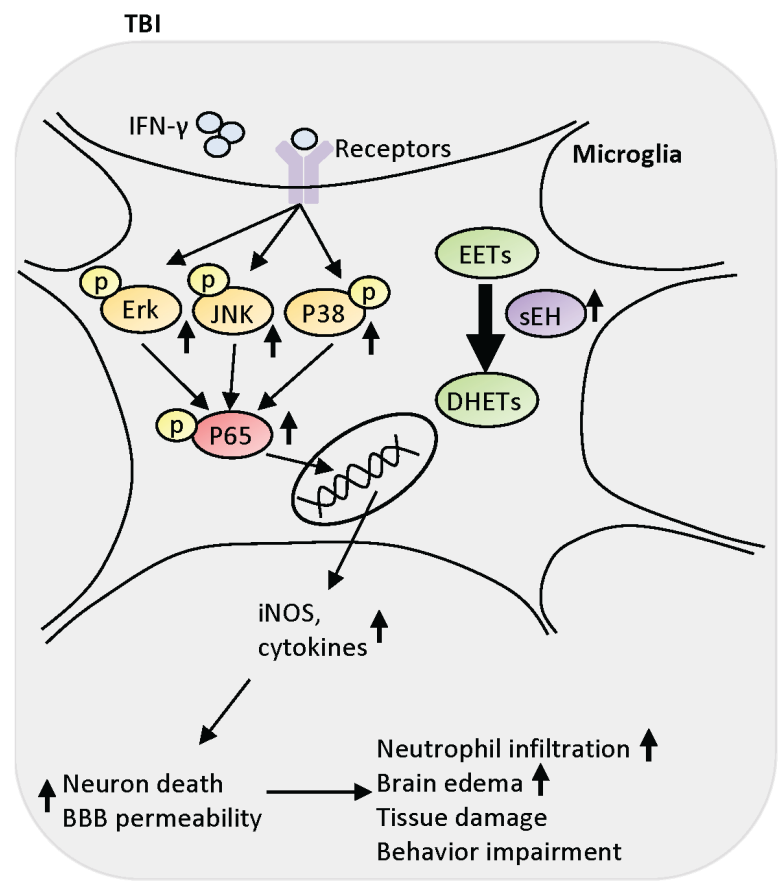

TBI+ sEH KO/AUDA treatment

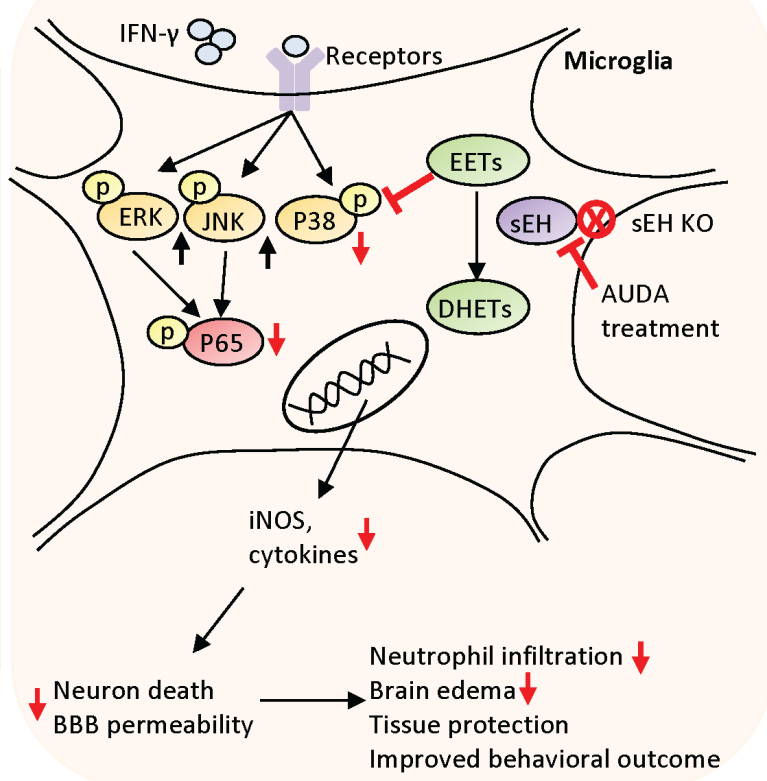

Figure 10: Schematic diagram of the mechanisms involved in SEH deletion or inhibition-induced protection in TBI mice. Deletion of sEH gene improved behavioral outcomes, and attenuated brain edema, neuronal death, brain tissue damage and BBB disruption. sEH deletion also reduced microglial activation, neutrophil infiltration, protein expression of proinflammatory mediators. In parallel, pharmacological inhibition of sEH using AUDA reduced brain edema, apoptosis and inflammatory responses in mouse TBI. In the microglial cells, AUDA attenuated LPS-stimulated or IFN- $\gamma$-stimulated NO production, and reduced activation of P38 and NF- $\mathrm{B}$ signaling. Treating LPS- or IFN- $\gamma$-stimulated microglia cells with AUDA reduced neuronal cell death induced by microglial conditioned media. Inhibition of sEH may protects against TBI by modulating the cytotoxic functions of microglia. 
mainly attributed to a reduction in cerebral inflammatory responses in the injured brain. Nevertheless, it remains undetermined whether sEH may affect BBB integrity via activating peripheral immune cells. Indeed, recent studies have reported that 8,9-EET inhibited LPS-induced B cell activation both in vivo and in vitro [37]. Additionally, pharmacological inhibition of sEH significantly reduced the number of neutrophils, alveolar macrophages, and lymphocytes in bronchoalveolar lavage fluid in tobacco smoke-exposed rats [38]. TBI induces a systemic inflammatory response including increased circulating neutrophil counts and plasma levels of inflammatory mediators [39], both of which contribute to TBI-induced brain edema [35]. Therefore, it is important to explore the peripheral effect by which $\mathrm{sEH}$ inhibition protects against TBI in future studies.

Following TBI, BBB disruption may occur via disruption of tight junction proteins (paracellular transport), increases in transcellular transport, mainly due to dysregulation of endothelial receptors and intracellular transporters, and loss of endothelial cells [40]. We demonstrated that deletion of $\mathrm{sEH}$ reduced BBB permeability but did not affect expression of tight junction proteins, suggesting that the protection of BBB integrity in sEH-KO mice may be via mechanisms other than increasing tight junction protein expression such as reducing transcellular transport or promoting endothelial cell survival. This explanation is supported by a previous study showing that experimental TBI induced an early increase in BBB permeability despite the integrity of the endothelial tight junctions [41]. Also, ultrastructural studies have shown that caveolae at endothelial cells are increased in vessel segments showing BBB disruption following rodent brain injury [42]. Furthermore, previous studies have demonstrated that post-translational modification of tight junction proteins without changing protein expression may alter junctional protein function and thus affect BBB integrity [43]. Our current results could not exclude the possibility that deletion of sEH may maintain BBB integrity via mechanisms such as reducing transcellular transport, promoting endothelial cell survival or attenuating post-translational modification of tight junction proteins. Therefore, the mechanisms by which $\mathrm{sEH}$ affects the BBB integrity remains to be elucidated in future studies.

Although recent studies have demonstrated that gene deletion or pharmacological inhibition of sEH elicits anti-inflammatory effects in vivo $[12,17,44]$, the direct contribution of $\mathrm{sEH}$ inhibition on the regulation of NF$\kappa \mathrm{B}$-dependent microglial activation has remained unclear. Microglial activation plays a key role in secondary injury after TBI by releasing reactive oxygen species as well as other neurotoxic molecules [6]. Our in vivo results demonstrated that deletion of $\mathrm{sEH}$ significantly reduced the number of activated microglia (hypertrophic and bushy morphologies) in the injured cortex at both 1 and
4 days after TBI. Both gene deletion and pharmacological inhibition attenuated the expression of inflammatory mediators (e.g., IL-1 $\beta$, IL-6, MIP-2, and MCP-1) in the injured brain at these two time-points. These findings are in line with previous studies in which deletion or pharmacological inhibition of $\mathrm{sEH}$ reduced microglial activation and cytokine expression in animal models of cerebral ischemia [12], spinal cord injury [44], and seizure [17]. Notably, we further used two in vitro models of microglial activation (LPS and IFN- $\gamma$ ) in the BV2 microglia cell line and in primary microglia to directly evaluate the effects of sEH inhibition or deletion on microglia. We found that AUDA treatment reduced iNOS expression, the release of NO, IL-1 $\beta$, IL-6 and MIP-2, and the activation of $\mathrm{NF}-\kappa \mathrm{B}$ and $\mathrm{P} 38$ in primary microglial cultures in response to LPS or IFN- $\gamma$ stimulation. Also, deletion of $\mathrm{sEH}$ attenuated the release of $\mathrm{NO}$ in IFN- $\gamma-$ stimulated primary microglial cultures. Our data advance previous observations supporting the hypothesis that $\mathrm{sEH}$ inhibition directly suppressed microglial activation by attenuating the P38-NF- $\mathrm{B}$ pathway. However, we did not distinguish microglia and macrophages in the in vivo experiment as there is no known cell-surface marker to distinguish brain-resident microglia from bloodderived macrophages. Therefore, we cannot exclude the involvement of blood-derived macrophages regarding the anti-inflammatory effect of sEH inhibition following mouse TBI as it is difficult to make the separation of brain resident microglia and blood-derived macrophages by immunohistology employed in this study. Methods to distinguish microglia from macrophages mainly depend on relative marker expression by flow cytometry based on levels of CD45 expression or generating bone marrow chimeras [45]. Another limitation of this study is that we used primary microglial cultures from rats instead of from mice as the number of microglia cells obtained from postnatal mouse brains was not large enough for Western blot analysis. However, in line with the fact that deletion of $\mathrm{sEH}$ in our study reduced microglial/macrophage activation and neuronal death following mouse TBI and that AUDA attenuated the neuronal cell death induced by microglia-conditioned media in the in vitro experiment, our observations suggest that the protection of damaged neurons by sEH inhibition was mediated by inhibition of microglia/macrophage-derived proinflammatory factors in the injured brain.

Previous studies have shown that MAPKs play critical roles in the cerebral inflammatory responses during acute brain injury $[30,46]$. MAPK signaling consists of P38 MAPK, JNK and ERK and is involved in microglial activation. Activation of MAPK signaling contributes to activation of transcriptional factors, including NF- $\kappa \mathrm{B}$, resulting in the upregulation of many proinflammatory genes (e.g., cytokines, chemokines, and iNOS) [30, 46]. These proinflammatory mediators can then further activate MAPKs and NF- $\kappa$ B, forming a positive feedback loop 
to amplify inflammatory signals. In the present study, AUDA attenuated phosphorylation of P38 but not JNK or ERK induced by LPS or IFN- $\gamma$, indicating that the P38MAPK pathway could represent a molecular target for sEH inhibition and thus mediate its anti-inflammatory properties in activated microglia. Our results are in accordance with a previous study demonstrating that EETs exerted anti-inflammatory effect by reducing the phosphorylation level of P38-MAPK in the culture of human bronchi [14]. However, pharmacological sEH inhibition has also been reported to inhibit the phosphorylation (activation) of JNK in human monocytes stimulated by LPS [47]. As activation of the MAPK pathways depends on the cell type, stimuli, duration of the stimulus as well as the cellular conditions [48], the inability of AUDA to affect the JNK pathway in microglia in our study may be due to different cell types. Another possibility for the selective inhibition of P38 MAPK is that, compared to P38, JNK signaling is more potent in regulating microglial survival [49], which might make JNK signaling more difficult to suppress. In addition, some studies show that EETs provide anti-inflammatory effects by activating PPAR $\gamma$ signaling $[14,50]$. STAT $1 / 3$ signalings are other important pathways involved in microglia-induced inflammation. STAT $1 / 3$ pathways have been shown to be involved in the inflammatory signaling cascades triggered by inflammatory stimuli such as LPS, IFN $-\gamma$ and other cytokines [51]. Activation of STAT 1 and 3 were also observed following rodent TBI [52]. Moreover, previous research indicated that exogenous EET administration inhibited STAT 3 activation in vitro [53]. Thus, the involvement of PPAR $\gamma$ and STAT $1 / 3$ signalings in the anti-inflammatory effects of sEH inhibition needs further investigation. Also, clarification of the role of MAPKs signaling in vivo is also one of our future directions.

Important considerations regarding the interpretation of our data are the multiple beneficial effects of EETs and $\mathrm{sEH}$ inhibition in the brain in addition to antiinflammatory effects. Therefore, the improvement in functional or histological outcomes in the current study may result from other beneficial effects of sEH inhibition. For example, EETs and sEHIs have been shown to suppress the reactive oxygen species (ROS) and apoptosis $[11,54,55]$, both of which are known to exacerbate TBI. Furthermore, EETs and sEH inhibitors are linked to angiogenesis and regulation of cerebral blood flow [11, $54,55]$. Also, a recent study demonstrated that EETs stimulated astrocyte-derived brain derived neurotrophic factor [13], an important neurotrophic factor for neuroprotection. Whether the enhancement of any of these actions by sEH inhibition contributes to neuroprotection against TBI needs to be determined. Additionally, we chose the pretreatment regimen and i.c.v. administration to allow maximal efficacy of central sEH inhibition. To explore the clinical relevance of sEH inhibition against
TBI, the study of post-treatment with different doses and times of sEH inhibitors will be investigated by our group.

Both astrocytes and microglia are activated following TBI and are involved in TBI-induced neuroinflammatory processes [56]. However, contrary to the detrimental effect in secreting inflammatory factors, astrocytes can elicit several protective actions, which can promote repair or reduce damage after TBI. For example, astrocytes produce anti-inflammatory factors to inhibit microglial activation in injury states [57]. Also, astrocytes secrete neurotrophic factors, including as brain-derived neurotrophic factor and vascular endothelial factor, both of which can protect neurons from ischemic injury [13, 58]. Therefore, this study focused on the effect of $\mathrm{sEH}$ deletion/inhibition on microglial activation. Nevertheless, it is also possible that astrocytes are involved in the antiinflammatory action of sEH deletion/inhibition.

sEH has two enzyme activities: the C-terminal hydrolase and N-terminal phosphatase activity [59]. The current study aimed to investigate the effect and molecular mechanisms of sEH hydrolase in the regulation of TBIinduced neuroinflammation. Thus, we used AUDA to inhibit the sEH hydrolase activity without affecting the phosphatase activity [60]. However, the phosphatase activity of sEH may also be involved in the pathogenesis of TBI. The phosphatase domain of sEH has been shown to negatively regulate VEGF-mediated endothelial NOS (eNOS) activity in vivo [61] and Akt-AMPK-mediated eNOS in vitro [62]. Since eNOS activity is implicated in mechanisms of neuronal injury and cerebral blood flow changes following brain injury [63], the sEH phosphatase activity may also participate in the pathogenesis of TBI.

In summary, our study shows that gene deletion or pharmacological inhibition of sEH protects against TBI (Figure 10). This neuroprotective effect is at least in part mediated by inhibition of $\mathrm{P} 38$ and NF- $\mathrm{kB}$ signaling in activated microglia, thereby suppressing the upregulation of inflammatory mediators. We conclude that $\mathrm{sEH}$ inhibition after TBI can reduce microglial activation to suppress inflammation and reduce subsequent neuronal death. Our findings suggest that sEH can be a potential therapeutic target to reduce brain damage and to improve functional outcome in survivors of TBI.

\section{MATERIALS AND METHODS}

\section{Animals}

All the experimental protocols were approved by the Institutional Animal care and Use Committee at Cheng Hsin General Hospital (Animal permit number CHGH102-18), and all animals were cared for in accordance with the Guide for the Care and Use of Laboratory Animals published by the US National Institutes of Health (NIH Publication No. 85-23, revised 1996). Six- to eight-weekold male sEH KO mice were purchased from Jackson 
Laboratory (Bar Harbor, Maine, USA). Six- to eightweek-old male C57BL/6 wild type (WT) mice were ordered from BioLASCO (Taipei, Taiwan) as controls. Mice were allowed free access to water and maintained on a 12-h/12-h dark cycle at a controlled temperature (22$25^{\circ} \mathrm{C}$ ) and humidity (40-60\%).

\section{Cell culture}

\section{Cell line cultures}

The neuroblastoma neuro-2A (N2A) cell line and the mouse microglial BV2 cell line were cultured as previous described [64, 65]. Briefly, N2A and microglial BV2 cell lines were cultured in Dulbecco's modified Eagle's media (DMEM; Gibco, Bethesda, MD, USA) supplemented with $10 \%$ heat-inactivated fetal bovine serum (FBS; Gibco), $100 \mathrm{U} / \mathrm{mL}$ penicillin and $100 \mu \mathrm{g} / \mathrm{mL}$ streptomycin in a humidified atmosphere of $5 \% \mathrm{CO}_{2}$ at $37^{\circ} \mathrm{C}$.

\section{Primary microglia culture}

Rat primary microglia cultures were prepared from the cerebral cortex of postnatal day 7 (P7) Wistar rats similar to a previous report [66]. Primary mouse microglia culture was prepared from the cortices of P7 WT and sEH KO mice. Briefly, cortices were chopped and digested in $20 \mathrm{U} / \mathrm{ml}$ papain for $40 \mathrm{~min}$ at $37^{\circ} \mathrm{C}$. The cells were plated with DMEM supplemented with $10 \%$ heat-inactivated FBS, $100 \mathrm{U} / \mathrm{mL}$ penicillin and $100 \mu \mathrm{g} /$ $\mathrm{mL}$ streptomycin. After 2 weeks, the microglial cells were separated from the astrocytes by shaking at $200 \mathrm{rpm}$ for $1 \mathrm{~h}\left(37^{\circ} \mathrm{C}\right)$. Non-adhered cells were eliminated, and microglial cells were re-plated on poly-L-lysine (Sigma)coated wells $\left(1 \times 10^{5}\right.$ cells per well $)$ in DMEM and $5 \%$ inactivated horse serum and used for the experiments 24 $\mathrm{h}$ later. The purity of cultured microglia was higher than 99\% under these conditions, as verified by GFAP and Iba1 staining.

\section{Culture drug treatment}

BV2 microglia or primary rat/mouse microglia were stimulated with either $100 \mathrm{ng} / \mathrm{mL}$ LPS or 10 $\mathrm{ng} / \mathrm{mL}$ IFN- $\gamma$ in the absence or presence of varying concentrations of AUDA (Cayman, Ann Arbor, MI, USA) or 14,15- epoxyeicosa-5(Z)-enoic acid (EEZE; 1 $\mu \mathrm{M}$, Cayman) for $1 \mathrm{~h}, 2 \mathrm{~h}, 6 \mathrm{~h}$ or $24 \mathrm{~h}$. To collect the conditioned media, BV2 microglia were plated and incubated with LPS or $10 \mathrm{ng} / \mathrm{mL} \mathrm{IFN-} \gamma$ in the absence (LPS-CM; IFN- $\gamma-\mathrm{CM}$ ) or presence of $10 \mu \mathrm{M}$ AUDA (LPS/AUDA-CM; IFN- $\gamma /$ AUDA-CM) for $24 \mathrm{~h}$. Cellfree supernatant fractions were applied to N2A cells for $48 \mathrm{~h}$ to evaluate the changes in cell viability and related parameters. Neuronal cell death was assessed by 3-[4,5-dimethyl-2-thiazolyl]-2,5-diphenyl-2-tetrazolium bromide (MTT) assays. The experiments were repeated four or five times with different batches of cultures.

\section{Experimental protocol}

Mice were randomized into different treatment groups by using computer-generated random numbers. All outcome measurements and analyses described below were performed in a blinded manner. Three studies were conducted. The first study examined the temporal profile and cellular localization of $\mathrm{sEH}$ expression after TBI. Assessment included Western blots $(n=5-6 /$ group) and double immunofluorescence labeling $(n=6 /$ group). The second study evaluated the neuroprotective and anti-inflammatory effects of $\mathrm{sEH}$ gene deletion. The assessments were as follows: 1) behavioral tests ( $\mathrm{n}=12$ /group); 2 ) histology ( $\mathrm{n}=6-7 /$ group); 3 ) brain water content and Evans blue dye extravasation $(n=6-7 /$ group) and 4) Western blot analysis, MMP-9 zymography ( $n=6-7 /$ group) and ELISA ( $n=4-7 /$ group). The third evaluated the neuroprotective and anti-inflammatory effects of AUDA, a selective sEH inhibitor, which has been widely used in experimental studies [19]. AUDA (10 $\mu \mathrm{M}$ in $0.5 \mu \mathrm{L}$ of $1 \% \mathrm{DMSO}$ ) or equal volume of vehicle (1\% DMSO) was i.c.v. injected $30 \mathrm{~min}$ before CCI and subsequently daily for 3 days (-30 $\mathrm{min}, 24 \mathrm{~h}, 48 \mathrm{~h}$ and 72h). The assessments were as follows: 1) brain water content ( $\mathrm{n}=7$ /group). 2) Western blot analysis, MMP-9 zymography ( $n=5-7 /$ group) and ELISA ( $n=4-7 /$ group). The 4-dose regimen was chosen because inflammatoryrelated signals peak between 1 and 4 days after CCI and decline thereafter [67].

\section{Controlled cortical impact injury}

Adult mice (8-12 weeks, 22-28 g) were subjected to CCI injury as previously described [68]. Briefly, mice were anesthetized with sodium pentobarbital via intraperitoneal injection (65 mg/kg; Rhone Merieux, Harlow, UK) and a 5-mm craniotomy over the right parietal cortex was made using a dental trephine drill, centered on the bregma, and $0.1 \mathrm{~mm}$ lateral to the midline. Injury was produced using a pneumatic piston with a $2.5-\mathrm{mm}$ rounded metal tip ( $4 \mathrm{~m} / \mathrm{sec}$ velocity, 2-mm deformation depth). The body temperature of the mice was maintained at 37.0 $\pm 0.5^{\circ} \mathrm{C}$ using a heated pad throughout the surgery and recovery period. Sham-operated mice underwent the same procedure as injured mice, except for CCI.

\section{Intracerebroventricular injection}

AUDA (Cayman, $10 \mu \mathrm{M}$ in $0.5 \mu \mathrm{L}$ of $1 \%$ DMSO) or equal volume of vehicle (1\% DMSO) was intracerebroventricularly injected at $30 \mathrm{~min}$ before CCI as previously described [69]. Briefly, a 30-gauge needle attached to a Hamilton syringe was inserted into the lateral ventricle $(0.5 \mathrm{~mm}$ posterior to the bregma, $1 \mathrm{~mm}$ right lateral to the midline, and $2 \mathrm{~mm}$ in depth). Then, AUDA or vehicle was infused with an infusion pump for $10 \mathrm{~min}$ at a rate of $0.05 \mu \mathrm{L} / \mathrm{min}$. The needle was removed from 
the infusion after 20 min to prevent reflux, and the CCI surgery was performed immediately thereafter. AUDA was then administered daily for another 3 days (30 min before $\mathrm{CCI}$, day 1 , day 2 and day 3 ) to continuously maintain the sEH inhibition effect after CCI.

\section{Behavioral testing}

Behavioral testing was performed before and at 1, 4, 7, 14, 21, and 28 days after CCI. Mice were pre-trained for both Rotarod and beam walking tests for 3 days.

\section{Modified neurological severity score}

The mNSS provides an index of motor, sensory, reflex, and balance ability [70]. A score of 0 corresponded to the inability to perform any test and absence of the tested reflex; thus, the higher the score, the more severe the injury. Neurological function was graded on a scale of 0-18 (normal score, 0; maximal deficit score, 18).

\section{Rotarod test}

An accelerating Rotarod was used to measure motor function and balance [71]. Briefly, the Rotarod speed was slowly increased from $6 \mathrm{rpm}$ to $42 \mathrm{rpm}$ within $7 \mathrm{~min}$, and the time when the mouse fell from the Rotarod was recorded.

\section{Beam walking test}

The test was used to assess motor function and coordination by measuring the ability of mice to cross an elevated beam [71]. The time for the mouse to traverse the beam (not to exceed $60 \mathrm{~s}$ ) and its hindlimb performance as it crossed the beam (based on a 1 to 7 rating scale) were recorded. A score of 7 was given when animals traversed the beam with two or less footslips; 6 was given when animals traversed the beam with less than $50 \%$ footslips; 5 was given for more than $50 \%$ but less than $100 \%$ footslips; 4 was given for $100 \%$ footslips; 3 was given for traversing the beam with the affected limb extended and not touching the surface of the beam; 2 was given when animals were able to balance on the beam but not traverse it; 1 was given when animals could not balance on the beam. For the Rotarod and beam walking tests, three measurements per trial were recorded $1 \mathrm{~h}$ before CCI (baseline) and at 1 , $4,7,14,21$, and 28 days post-CCI.

\section{Body weight measurement}

Body weight was measured $1 \mathrm{~h}$ before CCI (baseline) and at 1, 4, 7, 14, 21, and 28 days post-CCI using a digital scale.

\section{Brain water content}

Brain edema was assessed by measuring brain water content as a result of BBB breakdown after CCI. After decapitation (under anesthesia) at day 1 and day 4 post-injury, the ipsilateral and contralateral cortex (in a 4-mm coronal section, $2 \mathrm{~mm}$ from the frontal pole) and the cerebellum (as internal control) were weighed (wet weight), dried at $100^{\circ} \mathrm{C}$ for $24 \mathrm{~h}$, and reweighed (dry weight). Water content was determined as [(wet weightdry weight)/wet weight] $\times 100 \%$ [72] .

\section{Blood-brain barrier permeability}

A $2 \%$ solution of Evans blue in normal saline (4 $\mathrm{mL} / \mathrm{kg}$ of body weight) was injected into the tail vein and circulated for $1 \mathrm{~h}$ at day 1 and day 4 post-injury. The mice were then transcardially perfused with phosphate-buffered saline (PBS), and the ipsilateral hemisphere samples were homogenized in $1 \mathrm{~mL}$ of $60 \%$ trichloroacetic acid via sonication. After centrifugation at $4500 \mathrm{rpm}$ for $15 \mathrm{~min}$ at $4^{\circ} \mathrm{C}$, the supernatants were diluted with ethanol $(1: 4)$. The absorbance of each supernatant for the Evans blue dye was measured at $620 \mathrm{~nm}$ using a spectrophotometer (Genequant 1300, GE Healthcare, UK). EB concentrations were calculated and expressed as $\mu \mathrm{g} / \mathrm{g}$ brain tissue against a standard curve.

\section{Tissue processing and histology}

Mice were transcardially perfused by $0.9 \%$ sodium chloride following terminal anesthesia with sodium pentobarbital $\left(80 \mathrm{mg} \cdot \mathrm{kg}^{-1}\right.$, ip) at day 1 and day 4 for cresyl violet histology, FJB staining, TUNEL, and immunostaining, or at day 28 for cresyl violet staining. Brains were removed, post-fixed in $4 \%$ paraformaldehyde overnight, cryoprotected with $30 \%$ sucrose, and then sectioned coronally at $10 \mu \mathrm{m}$ from the level of the olfactory bulbs to the visual cortex.

\section{FJB staining}

FJB (Chemicon, Temecula, CA, USA) is a polyanionic fluorescein derivative that binds with high sensitivity and specificity to degenerating neurons. Briefly, sections were rehydrated in graded ethanol solutions (100 and $70 \%, 5 \mathrm{~min}$ each) and distilled water, incubated in $0.06 \% \mathrm{KMnO}_{4}$ for $30 \mathrm{~min}$, rinsed in distilled water for 2 min, incubated in a $0.001 \%$ solution of FJB for $30 \mathrm{~min}$, and observed under a fluorescence microscope (Olympus BX-51; Olympus, Tokyo, Japan) at 450-490 nm.

\section{TUNEL assay}

TUNEL assay is used to label DNA fragmentation with fluorescein isothiocyanate (In situ Cell Death Detection Kit; Roche Molecular Biochemicals, Mannheim, Germany). Sections were incubated in TUNEL reaction mixture containing terminal deoxynucleotidyl transferase (TdT) for $60 \mathrm{~min}$ at $37^{\circ} \mathrm{C}$. Sections were then observed and photographed under a fluorescence microscope (Olympus BX-51) with blue (450 490 nm) excitation 
light. Negative controls were obtained by omission of the enzyme TdT.

\section{Immunohistochemistry staining}

Immunohistochemical analyses were carried out as previously described [72]. After quenching of endogenous peroxidase activity and blocking of nonspecific binding with $10 \%$ normal goat serum, sections were incubated with rabbit anti-myeloperoxidase (MPO, a neutrophil marker; 1:1000; Dako, Carpinteria, CA, USA) or rabbit anti-Iba1 (a microglia/macrophage marker; 1:1000; Wako Pure Chemical Industries, Osaka, Japan) primary antibodies overnight. Further colorimetric detection was processed according to the instructions of a Vectastain Elite ABC Kit (Vector Laboratories, Burlingame, CA, USA) using diaminobenzidine as a peroxidase substrate. The specificity of the staining reaction was assessed in several control procedures, including omission of the primary antibody and substitution of the primary antibody with non-immune rabbit serum.

\section{Double immunofluorescence staining}

To assess the cellular source of $\mathrm{sEH}$, double immunofluorescence labeling was performed by simultaneous incubation of primary antibodies (antisEH, 1:1000; Santa Cruz Biotechnology, Santa Cruz, CA, USA) with mouse anti-neuronal nuclei antigen (NeuN, a neuronal marker; 1:100, Millipore, Billerica, MA, USA), rat anti-glial fibrillary acidic protein (GFAP, an astrocyte marker ; 1:200; Invitrogen, Camarillo, CA, USA), mouse anti-OX42 (a microglia/macrophage marker; 1:100; Wako), or rat anti-CD31(an endothelial cell marker; 1:100; BD Biosciences, CA, USA). Sections were incubated overnight at $4{ }^{\circ} \mathrm{C}$ with anti-sEH antibody plus one of the antibodies to a specific cellular marker. To assess proinflammatory (M1) and anti-inflammatory (M2) microglia/macrophages, sections were incubated overnight at $4^{\circ} \mathrm{C}$ with rabbit anti-Iba1 $(1: 1,000$; Wako), together with rat anti-CD16/32 (a classical M1 activation marker; 1:100; BD Biosciences), mouse anti-CD206 (an alternative M2 activation marker; 1:100; Bio-Rad Laboratories, Hercules, CA, USA) or rabbit anti-arginase 1 (an alternative M2 activation marker; 1:100; BD Biosciences). Sections were then washed, and incubated with Alexa Fluor 488- or Alexa Fluor 594-conjugated secondary antibodies (1:400; Molecular Probes, Eugene, OR) for $2 \mathrm{~h}$. All sections were observed and photographed under a fluorescence microscope (Olympus BX-51). For primary microglial cultures, cells were plated onto poly-L-lysine coated cover slips in 24-well plate and were then incubated overnight with mouse anti-OX42 (1:100; Wako), together with rabbit-anti-iNOS (1:100; Chemicon), rabbit anti-p-P65, rabbit anti-p-P38, rabbit anti-p-JNK or rabbit anti-pERK p44/42 from Cell Signaling (Danvers, MA, USA).
Subsequently the cells were incubated with Alexa Fluor 488- or Alexa Fluor 594-conjugated secondary antibodies (1:500; Molecular Probes, Eugene, OR) for $2 \mathrm{~h}$ and examined under a fluorescence microscope.

\section{Contusion volume and hemispheric enlargement assessment}

Contusion volumes, residual tissue ratios, and hemispheric enlargement ratios were quantified using cresyl violet-stained sections at 20 rostral-caudal levels that were spaced $200 \mu \mathrm{m}$ apart as previously described [69]. Sections were analyzed using ImageJ software (Version 1.50i, National Institutes of Health, Bethesda, MD, USA). The volume measurement was computed by summation of the areas multiplied by the interslice distance $(200 \mu \mathrm{m})$. The preservation of cerebral tissue was evaluated by the ratio of the volume of the remaining ipsilateral cerebral hemisphere to the volume of the corresponding contralateral cerebral hemisphere. Brain edema was assessed by calculating the percentage of hemispheric enlargement using the following formula: ([ipsilateral hemisphere volume - contralateral hemisphere volume] / contralateral hemisphere volume) $\times 100 \%$. Analysis was performed by two experimenters who were blinded to all animal groups. Inter-rater reliability was within $10 \%$.

\section{Quantification of FJB, TUNEL, MPO and Iba1 staining}

FJB, TUNEL, MPO and Iba1 stainings were quantified on three consecutive sections from the injury core at the level of $0.74 \mathrm{~mm}$ from the bregma. FJB-, TUNEL-, MPO-, and Iba1-positive cells were counted at a magnification of $200 \times$ in 3 randomly selected, nonoverlapping fields with areas of $920 \times 860 \mu \mathrm{m}^{2}$. Iba1positive resting microglia/macrophages were defined as resting if they contained relatively small cell bodies $(<7.5 \mu \mathrm{m}$ in diameter) with long slender processes [73]. Microglia were defined as activated when a cell body increased in size compared to resting microglia with short, thick processes and intense immunointensity. Activated microglia/macrophages were defined based on a combination of morphological criteria and a cell body diameter cutoff of $7.5 \mu \mathrm{m}$. FJB-, MPO- and Iba1positive cells were expressed as cells/field. Quantification of TUNEL staining was expressed as (TUNEL-stained nuclei/DAPI-stained nuclei) $\times 100 \%$. Analysis was performed by two experimenters who were blinded to all animal groups. Inter-rater reliability was within $10 \%$.

\section{Western blots}

Western blots were performed as previously described [68]. A 4-mm coronal section from the injured 
area over the right parietal cortex was collected at $1 \mathrm{~h}, 3$ h, 6 h, 12 h, 1 day, 4 days and 7 days following CCI or sham surgery. The liver sample was collected from the WT mouse as a positive control for the sEH antibody. BV2 cells were collected at $24 \mathrm{~h}, \mathrm{~N} 2 \mathrm{~A}$ cells were collected at $48 \mathrm{~h}$, and primary microglia were collected at $1 \mathrm{~h}, 2 \mathrm{~h}, 6 \mathrm{~h}$, and $24 \mathrm{~h}$ post-LPS or IFN- $\gamma$ stimulation. All samples were centrifuged at $14,000 \times \mathrm{g}$ for $30 \mathrm{~min}$, and supernatants were used for further protein analysis. Protein concentration was determined by protein assay dye reagent at $595 \mathrm{~nm}$. Protein samples were boiled with loading buffer at $100^{\circ} \mathrm{C}$ for $5 \mathrm{~min}$, separated by electrophoresis on $8-12 \%$ sodium dodecyl sulfate-polyacrylamide gels, and transferred to Immobilon-P membranes (Millipore). Membranes were blocked with 5\% milk in PBS-XT and probed with primary antibodies including rabbit anti-cleaved caspase-3 (1:1000), rabbit anti-p-P38 (1:1000), rabbit anti-P38 (1:2000), rabbit anti-p-ERK p44/42 (ERK p44/42; Thr202/ Tyr204, 1:1000), rabbit anti-ERK (1:2000), rabbit anti-pJNK (Thr183/Tyr185, 1:1000), rabbit anti-JNK (1:2000), rabbit anti-p-P65(1:1000) from Cell Signaling (Danvers, MA, USA), rabbit anti-ZO-1 (1:1000) and rabbit anticlaudin-5 (1:1000) from Invitrogen, mouse anti-iNOS (1:1000; Cayman), and mouse anti- $\beta$-actin (1:10000, sigma-Aldrich, St. Louis, MO, USA). The membranes were then incubated with horseradish peroxidase-linked anti-rabbit or anti-mouse secondary antibodies (1:5000, Santa Cruz) for $1 \mathrm{~h}$ at $4^{\circ} \mathrm{C}$. Protein band intensities were quantified using ImageJ software and were normalized to the corresponding $\beta$-actin intensity.

\section{Gelatin gel zymography}

Zymography was performed as previously described [72]. Briefly, protein samples were prepared similar to Western blot but without boiling. Samples were equally loaded and separated by $10 \%$ triglycine gel with $0.1 \%$ gelatin as the substrate. After separation, the gel was washed in distilled water, re-natured for $1 \mathrm{~h}$ with $2.5 \%$ Triton X-100 buffer at room temperature, and incubated for $48 \mathrm{~h}$ with developing buffer $(0.05 \mathrm{M}$ Tris- $\mathrm{HCl} \mathrm{pH}$ 7.5, $0.2 \mathrm{~mol} / \mathrm{L} \mathrm{NaCl}, 5 \mathrm{mmol} / \mathrm{L} \mathrm{CaCl}_{2}, 0.05 \%$ Brij-35, 0.2 $\mathrm{mmol} / \mathrm{L} \mathrm{NaN}_{3}$ ) at $37^{\circ} \mathrm{C}$. Then, the gel was stained with 0.05\% Coomassie R-250 dye (Sigma-Aldrich) for 30 min and appropriately de-stained. Gelatinolytic activity (MMP-9, $97 \mathrm{kDa}$ ) was determined as showing clear bands at the appropriate molecular weights.

\section{Enzyme-linked immunosorbent assay}

Protein samples were collected as in Western blot at day 1 and day 4 following CCI or sham surgery and in primary microglia cultures. IL-1 $\beta$, IL-6, MIP-2, MCP1 from R\&D Systems (Minneapolis, MN, USA), EETs (MyBiosource, San Diego, CA, USA), and 14,15-DHET (Detroit R\&D Inc., Detroit, MI, USA) were measured using ELISA kit. All samples and standards were assayed in duplicate according to the manufacturer's instructions.

\section{NO production and cell viability}

NO production was assessed by measuring the nitrite levels of the culture supernatants with Griess reagent (Sigma-Aldrich). Cell viability was assessed using MTT reduction assay (Sigma-Aldrich). The experiments were repeated four times with different batches of primary cultures.

\section{Statistical analyses}

Data are presented as the mean and standard error of the mean (mean \pm S.E.M). One-way or two-way analysis of variance (ANOVA) followed by post-hoc Bonferroni evaluation was used for multiple groups to determine significant differences on behavioral tasks, Western blots, brain water contents, BBB permeability, MMP-9 zymmography, ELISA and immunofluoresent stainings. Student's t-test was used to test the difference between two groups on histology. Statistical significance was set at $P<0.05$.

\section{CONFLICTS OF INTEREST}

The authors declare that they have no conflicts of interest.

\section{FUNDING}

This study was supported by grants from the Ministry of Science and Technology of Taiwan (no. MOST 101-2314-B-350-001-MY3 and MOST 103-2314-B-182A009-MY2) and Cheng Hsin General Hospital Foundation (no. CHGH104-29 and CHGH104-30).

\section{REFERENCES}

1. Langlois JA, Rutland-Brown W, Wald MM. The epidemiology and impact of traumatic brain injury: a brief overview. J Head Trauma Rehabil. 2006; 21:375-378.

2. McConeghy KW, Hatton J, Hughes L, Cook AM. A review of neuroprotection pharmacology and therapies in patients with acute traumatic brain injury. CNS Drugs. 2012; 26:613-636.

3. Holmin S, Soderlund J, Biberfeld P, Mathiesen T. Intracerebral inflammation after human brain contusion. Neurosurgery. 1998; 42:291-298; discussion 298-299.

4. Morganti-Kossmann MC, Rancan M, Stahel PF, Kossmann T. Inflammatory response in acute traumatic brain injury: a double-edged sword. Curr Opin Crit Care. 2002; 8:101-105.

5. Marmarou A. Pathophysiology of traumatic brain edema: current concepts. Acta Neurochir Suppl. 2003; 86:7-10. 
6. Loane DJ, Byrnes KR. Role of microglia in neurotrauma. Neurotherapeutics. 2010; 7:366-377.

7. Haase G, Pettmann B, Raoul C, Henderson CE. Signaling by death receptors in the nervous system. Curr Opin Neurobiol. 2008; 18:284-291.

8. Jara JH, Singh BB, Floden AM, Combs CK. Tumor necrosis factor alpha stimulates NMDA receptor activity in mouse cortical neurons resulting in ERK-dependent death. J Neurochem. 2007; 100:1407-1420.

9. Siopi E, Llufriu-Daben G, Cho AH, Vidal-Lletjos S, Plotkine M, Marchand-Leroux C, Jafarian-Tehrani M. Etazolate, an alpha-secretase activator, reduces neuroinflammation and offers persistent neuroprotection following traumatic brain injury in mice. Neuropharmacology. 2013; 67:183-192.

10. Skovira JW, Wu J, Matyas JJ, Kumar A, Hanscom M, Kabadi SV, Fang R, Faden AI. Cell cycle inhibition reduces inflammatory responses, neuronal loss, and cognitive deficits induced by hypobaria exposure following traumatic brain injury. J Neuroinflammation. 2016; 13:299.

11. Iliff JJ, Jia J, Nelson J, Goyagi T, Klaus J, Alkayed NJ. Epoxyeicosanoid signaling in CNS function and disease. Prostaglandins Other Lipid Mediat. 2010; 91:68-84.

12. Liu Y, Wan Y, Fang Y, Yao E, Xu S, Ning Q, Zhang G, Wang W, Huang X, Xie M. Epoxyeicosanoid signaling provides multi-target protective effects on neurovascular unit in rats after focal ischemia. J Mol Neurosci. 2016; 58:254-265.

13. Yuan L, Liu J, Dong R, Zhu J, Tao C, Zheng R, Zhu S. 14,15-epoxyeicosatrienoic acid promotes production of brain derived neurotrophic factor from astrocytes and exerts neuroprotective effects during ischaemic injury. Neuropathol Appl Neurobiol. 2016; 42:607-620.

14. Morin C, Sirois M, Echave V, Albadine R, Rousseau E. 17,18-epoxyeicosatetraenoic acid targets PPARgamma and p38 mitogen-activated protein kinase to mediate its antiinflammatory effects in the lung: role of soluble epoxide hydrolase. Am J Respir Cell Mol Biol. 2010; 43:564-575.

15. Hye Khan MA, Neckar J, Manthati V, Errabelli R, Pavlov TS, Staruschenko A, Falck JR, Imig JD. Orally active epoxyeicosatrienoic acid analog attenuates kidney injury in hypertensive Dahl salt-sensitive rat. Hypertension. 2013; 62:905-913.

16. Qin X, Wu Q, Lin L, Sun A, Liu S, Li X, Cao X, Gao T, Luo P, Zhu X, Wang X. Soluble epoxide hydrolase deficiency or inhibition attenuates MPTP-induced parkinsonism. Mol Neurobiol. 2015; 52:187-195.

17. Hung YW, Hung SW, Wu YC, Wong LK, Lai MT, Shih YH, Lee TS, Lin YY. Soluble epoxide hydrolase activity regulates inflammatory responses and seizure generation in two mouse models of temporal lobe epilepsy. Brain Behav Immun. 2015; 43:118-129.

18. Martini RP, Ward J, Siler DA, Eastman JM, Nelson JW, Borkar RN, Alkayed NJ, Dogan A, Cetas JS. Genetic variation in soluble epoxide hydrolase: association with outcome after aneurysmal subarachnoid hemorrhage. J Neurosurg. 2014; 121:1359-1366.

19. Simpkins AN, Rudic RD, Schreihofer DA, Roy S, Manhiani M, Tsai HJ, Hammock BD, Imig JD. Soluble epoxide inhibition is protective against cerebral ischemia via vascular and neural protection. Am J Pathol. 2009; 174:2086-2095.

20. Zhang W, Otsuka T, Sugo N, Ardeshiri A, Alhadid YK, Iliff JJ, DeBarber AE, Koop DR, Alkayed NJ. Soluble epoxide hydrolase gene deletion is protective against experimental cerebral ischemia. Stroke. 2008; 39:2073-2078.

21. Strauss KI, Gruzdev A, Zeldin DC. Altered behavioral phenotypes in soluble epoxide hydrolase knockout mice: effects of traumatic brain injury. Prostaglandins Other Lipid Mediat. 2013; 104-105:18-24.

22. Zhou H, Chen L, Gao X, Luo B, Chen J. Moderate traumatic brain injury triggers rapid necrotic death of immature neurons in the hippocampus. J Neuropathol Exp Neurol. 2012; 71:348-359.

23. Raghupathi R, Conti AC, Graham DI, Krajewski S, Reed JC, Grady MS, Trojanowski JQ, McIntosh TK. Mild traumatic brain injury induces apoptotic cell death in the cortex that is preceded by decreases in cellular Bcl-2 immunoreactivity. Neuroscience. 2002; 110:605-616.

24. Nag S, Manias JL, Stewart DJ. Pathology and new players in the pathogenesis of brain edema. Acta Neuropathol. 2009; 118:197-217.

25. Zweckberger K, Eros C, Zimmermann R, Kim SW, Engel D, Plesnila N. Effect of early and delayed decompressive craniectomy on secondary brain damage after controlled cortical impact in mice. J Neurotrauma. 2006; 23:1083-1093.

26. Taylor RA, Sansing LH. Microglial responses after ischemic stroke and intracerebral hemorrhage. Clin Dev Immunol. 2013; 2013:746068.

27. Hu X, Leak RK, Shi Y, Suenaga J, Gao Y, Zheng P, Chen J. Microglial and macrophage polarization-new prospects for brain repair. Nat Rev Neurol. 2015; 11:56-64.

28. Colton CA. Heterogeneity of microglial activation in the innate immune response in the brain. J Neuroimmune Pharmacol. 2009; 4:399-418.

29. Zhang R, Liu Y, Yan K, Chen L, Chen XR, Li P, Chen FF, Jiang XD. Anti-inflammatory and immunomodulatory mechanisms of mesenchymal stem cell transplantation in experimental traumatic brain injury. J Neuroinflammation. 2013; 10:106.

30. Koistinaho M, Koistinaho J. Role of p38 and p44/42 mitogen-activated protein kinases in microglia. Glia. 2002; 40:175-183.

31. Tanaka H, Kamita SG, Wolf NM, Harris TR, Wu Z, Morisseau C, Hammock BD. Transcriptional regulation of the human soluble epoxide hydrolase gene EPHX2. Biochim Biophys Acta. 2008; 1779:17-27. 
32. Lotocki G, de Rivero Vaccari JP, Perez ER, Alonso OF, Curbelo K, Keane RW, Dietrich WD. Therapeutic hypothermia modulates TNFR1 signaling in the traumatized brain via early transient activation of the JNK pathway and suppression of XIAP cleavage. Eur J Neurosci. 2006; 24:2283-2290.

33. Raghupathi R, McIntosh TK. Regionally and temporally distinct patterns of induction of c-fos, c-jun and junB mRNAs following experimental brain injury in the rat. Brain Res Mol Brain Res. 1996; 37:134-144.

34. Yang K, Mu XS, Xue JJ, Whitson J, Salminen A, dixon CE, Liu PK, Hayes RL. Increased expression of c-fos mRNA and AP-1 transcription factors after cortical impact injury in rats. Brain Res. 1994; 664:141-147.

35. Das M, Mohapatra S, Mohapatra SS. New perspectives on central and peripheral immune responses to acute traumatic brain injury. J Neuroinflammation. 2012; 9:236.

36. Siler DA, Berlow YA, Kukino A, Davis CM, Nelson JW, Grafe MR, Ono H, Cetas JS, Pike M, Alkayed NJ. Soluble epoxide hydrolase in hydrocephalus, cerebral edema, and vascular inflammation after subarachnoid hemorrhage. Stroke. 2015; 46:1916-1922.

37. Gao Y, Feng J, Ma K, Zhou Z, Zhu Y, Xu Q, Wang X. 8,9-Epoxyeicosatrienoic acid inhibits antibody production of B lymphocytes in mice. PLoS One. 2012; 7:e40258.

38. Smith KR, Pinkerton KE, Watanabe T, Pedersen TL, Ma SJ, Hammock BD. Attenuation of tobacco smoke-induced lung inflammation by treatment with a soluble epoxide hydrolase inhibitor. Proc Natl Acad Sci U S A. 2005; 102:2186-2191.

39. Liao Y, Liu P, Guo F, Zhang ZY, Zhang Z. Oxidative burst of circulating neutrophils following traumatic brain injury in human. PLoS One. 2013; 8:e68963.

40. Shlosberg D, Benifla M, Kaufer D, Friedman A. Bloodbrain barrier breakdown as a therapeutic target in traumatic brain injury. Nat Rev Neurol. 2010; 6:393-403.

41. Povlishock JT, Becker DP, Sullivan HG, Miller JD. Vascular permeability alterations to horseradish peroxidase in experimental brain injury. Brain Res. 1978; 153:223-239.

42. Nag S, Manias JL, Stewart DJ. Expression of endothelial phosphorylated caveolin-1 is increased in brain injury. Neuropathol Appl Neurobiol. 2009; 35:417-426.

43. Cummins PM. Occludin: one protein, many forms. Mol Cell Biol. 2012; 32:242-250.

44. Chen X, Chen X, Huang X, Qin C, Fang Y, Liu Y, Zhang G, Pan D, Wang W, Xie M. Soluble epoxide hydrolase inhibition provides multi-target therapeutic effects in rats after spinal cord injury. Mol Neurobiol. 2016; 53:1565-1578.

45. Greter M, Lelios I, Croxford AL. Microglia versus myeloid cell nomenclature during brain inflammation. Front Immunol. 2015; 6:249.

46. Sun J, Nan G. The mitogen-activated protein kinase (MAPK) signaling pathway as a discovery target in stroke. J Mol Neurosci. 2016; 59:90-98.
47. Sanders WG, Morisseau C, Hammock BD, Cheung AK, Terry CM. Soluble epoxide hydrolase expression in a porcine model of arteriovenous graft stenosis and antiinflammatory effects of a soluble epoxide hydrolase inhibitor. Am J Physiol Cell Physiol. 2012; 303:C278-290.

48. Wagner EF, Nebreda AR. Signal integration by JNK and p38 MAPK pathways in cancer development. Nat Rev Cancer. 2009; 9:537-549.

49. Svensson C, Part K, Kunnis-Beres K, Kaldmae M, Fernaeus SZ, Land T. Pro-survival effects of JNK and p38 MAPK pathways in LPS-induced activation of BV-2 cells. Biochem Biophys Res Commun. 2011; 406:488-492.

50. Liu Y, Zhang Y, Schmelzer K, Lee TS, Fang X, Zhu Y, Spector AA, Gill S, Morisseau C, Hammock BD, Shyy JY. The antiinflammatory effect of laminar flow: the role of PPARgamma, epoxyeicosatrienoic acids, and soluble epoxide hydrolase. Proc Natl Acad Sci U S A. 2005; 102:16747-16752.

51. Zhou D, Huang C, Lin Z, Zhan S, Kong L, Fang C, Li J. Macrophage polarization and function with emphasis on the evolving roles of coordinated regulation of cellular signaling pathways. Cell Signal. 2014; 26:192-197.

52. Zhao JB, Zhang Y, Li GZ, Su XF, Hang CH. Activation of JAK2/STAT pathway in cerebral cortex after experimental traumatic brain injury of rats. Neurosci Lett. 2011; 498:147-152.

53. Zhou C, Huang J, Chen J, Lai J, Zhu F, Xu X, Wang DW. CYP2J2-derived EETs attenuated angiotensin II-induced adventitial remodeling via reduced inflammatory response. Cell Physiol Biochem. 2016; 39:721-739.

54. Imig JD, Hammock BD. Soluble epoxide hydrolase as a therapeutic target for cardiovascular diseases. Nat Rev Drug Discov. 2009; 8:794-805.

55. Revermann M. Pharmacological inhibition of the soluble epoxide hydrolase-from mouse to man. Curr Opin Pharmacol. 2010; 10:173-178.

56. Karve IP, Taylor JM, Crack PJ. The contribution of astrocytes and microglia to traumatic brain injury. Br J Pharmacol. 2016; 173:692-702.

57. Kim JH, Min KJ, Seol W, Jou I, Joe EH. Astrocytes in injury states rapidly produce anti-inflammatory factors and attenuate microglial inflammatory responses. J Neurochem. 2010; 115:1161-1171.

58. Zhang Y, Hong G, Lee KS, Hammock BD, Gebremedhin D, Harder DR, Koehler RC, Sapirstein A. Inhibition of soluble epoxide hydrolase augments astrocyte release of vascular endothelial growth factor and neuronal recovery after oxygen-glucose deprivation. J Neurochem. 2017; 140:814-825.

59. Cronin A, Mowbray S, Durk H, Homburg S, Fleming I, Fisslthaler B, Oesch F, Arand M. The N-terminal domain of mammalian soluble epoxide hydrolase is a phosphatase. Proc Natl Acad Sci U S A. 2003; 100:1552-1557. 
60. Imig JD, Hammock BD. Soluble epoxide hydrolase as a therapeutic target for cardiovascular diseases. Nat Rev Drug Discov. 2009; 8:794-805.

61. Hou HH, Hammock BD, Su KH, Morisseau C, Kou YR, Imaoka S, Oguro A, Shyue SK, Zhao JF, Lee TS. N-terminal domain of soluble epoxide hydrolase negatively regulates the VEGF-mediated activation of endothelial nitric oxide synthase. Cardiovasc Res. 2012; 93:120-129.

62. Hou HH, Liao YJ, Hsiao SH, Shyue SK, Lee TS. Role of phosphatase activity of soluble epoxide hydrolase in regulating simvastatin-activated endothelial nitric oxide synthase. Sci Rep. 2015; 5:13524.

63. Srivastava K, Bath PM, Bayraktutan U. Current therapeutic strategies to mitigate the eNOS dysfunction in ischaemic stroke. Cell Mol Neurobiol. 2012; 32:319-336.

64. Chen CC, Hung TH, Lee CY, Wang LF, Wu CH, $\mathrm{Ke} \mathrm{CH}$, Chen SF. Berberine protects against neuronal damage via suppression of glia-mediated inflammation in traumatic brain injury. PLoS One. 2014; 9:e115694.

65. Wu CH, Chen CC, Lai CY, Hung TH, Lin CC, Chao M, Chen SF. Treatment with TO901317, a synthetic liver X receptor agonist, reduces brain damage and attenuates neuroinflammation in experimental intracerebral hemorrhage. J Neuroinflammation. 2016; 13:62.

66. Cipriani R, Chara JC, Rodriguez-Antiguedad A, Matute C. FTY720 attenuates excitotoxicity and neuroinflammation. J Neuroinflammation. 2015; 12:86.

67. Turtzo LC, Lescher J, Janes L, Dean DD, Budde MD, Frank JA. Macrophagic and microglial responses after focal traumatic brain injury in the female rat. $\mathrm{J}$ Neuroinflammation. 2014; 11:82.
68. Chen SF, Tsai HJ, Hung TH, Chen CC, Lee CY, Wu CH, Wang PY, Liao NC. Salidroside improves behavioral and histological outcomes and reduces apoptosis via PI3K/Akt signaling after experimental traumatic brain injury. PLoS One. 2012; 7:e45763.

69. Wu CH, Hung TH, Chen $\mathrm{CC}$, Ke CH, Lee CY, Wang PY, Chen SF. Post-injury treatment with 7,8-dihydroxyflavone, a TrkB receptor agonist, protects against experimental traumatic brain injury via PI3K/Akt signaling. PLoS One. 2014; 9:e113397.

70. Chen SF, Hsu CW, Huang WH, Wang JY. Postinjury baicalein improves histological and functional outcomes and reduces inflammatory cytokines after experimental traumatic brain injury. Br J Pharmacol. 2008; 155:1279-1296.

71. Chen CC, Hung TH, Wang YH, Lin CW, Wang PY, Lee $\mathrm{CY}$, Chen SF. Wogonin improves histological and functional outcomes, and reduces activation of TLR4/NF-kappaB signaling after experimental traumatic brain injury. PLoS One. 2012; 7:e30294.

72. Chang CF, Chen SF, Lee TS, Lee HF, Chen SF, Shyue SK. Caveolin-1 deletion reduces early brain injury after experimental intracerebral hemorrhage. Am J Pathol. 2011; 178:1749-1761.

73. Batchelor PE, Liberatore GT, Wong JY, Porritt MJ, Frerichs F, Donnan GA, Howells DW. Activated macrophages and microglia induce dopaminergic sprouting in the injured striatum and express brain-derived neurotrophic factor and glial cell line-derived neurotrophic factor. J Neurosci. 1999; 19:1708-1716. 